\title{
Performance of $\mathrm{YSZ}$ and $\mathrm{Gd}_{2} \mathrm{Zr}_{2} \mathrm{O}_{7} / \mathrm{YSZ}$ double layer thermal barrier coatings in burner rig
} tests

Robert Vaßen*, Emine Bakan, Daniel Mack, Sigrid Schwartz-Lückge, Doris Sebold, Yoo Jung Sohn, Dapeng Zhou, Olivier Guillon

Forschungszentrum Jülich GmbH, Institute of Energy and Climate Research IEK-1, 52425 Jülich,

\section{Germany}

*Corresponding Author. Forschungszentrum Jülich GmbH, Institute of Energy and Climate Research IEK-1, 52425 Jülich, Germany. Tel: +49 246161 6108; Fax: +49 246161 2455, e-mail: r.vassen@fz-juelich.de.

\begin{abstract}
Double layer thermal barrier coatings (TBCs) consisting of a $\mathrm{Gd}_{2} \mathrm{Zr}_{2} \mathrm{O}_{7}$ (GZO) top and an ytrria stabilized zirconia (YSZ) interlayer have been tested in a burner rig facility and the results compared to the ones of conventional YSZ single layers. In order to gain insight in the high temperature capability of the alternative TBC material, high surface temperatures of up to $1550{ }^{\circ} \mathrm{C}$ have been chosen while keeping the bond coat temperature similar. It turned out that the performance of all systems is largely depending on the microstructure of the coatings especially reduced porosity levels of GZO being detrimental. In addition, it was more difficult in GZO than in YSZ coatings to obtain highly porous and still properly bonded microstructures. Another finding was the reduced lifetime with increasing surface temperatures, the amount of reduction is depending on the investigated system. The reasons for this behavior are analyzed and discussed in detail.
\end{abstract}

\section{Introduction}

Thermal barrier coating systems consist of a metallic intermediate bond coat layer (often NiCoCrAlY compositions are used) and a ceramic topcoat. The bond coat layer allows an improved bonding of the ceramic topcoat to the substrate and protects the substrate from oxidation by forming a protective scale (thermally grown oxide (TGO), often alumina-based). This scale introduces additional stresses into the TBC system and often plays an important role in the degradation and failure of TBC systems. In this study the bond coat has always the same NiCoCrAlY composition as the major focus is on the influence and performance of the ceramic topcoats.

The main function of the ceramic top coat in the TBC systems is providing thermal insulation for the metallic engine parts. Since it was introduced in the 1970s, 6-8 wt. \% yttria-stabilized zirconia (YSZ) has 
been the material of choice for this purpose [1], because it shows a unique combination of desired properties. These properties include good thermal stability (i.e. limited changes of porosity (sintering) and phase transformation during high temperature treatment), low thermal conductivity, high coefficient of thermal expansion (CTE) in combination with a high fracture toughness which are the main required properties for the ceramic top coat on metallic components. The $7.4 \mathrm{wt}$. \% YSZ has a high melting point $\left(2700^{\circ} \mathrm{C}\right)$ and a low thermal conductivity of 2.5 to $3.0 \mathrm{~W} / \mathrm{mK}$ between room temperature and $1000{ }^{\circ} \mathrm{C}$ [2]. YSZ shows for typical oxide ceramics a high CTE $\left(11 \times 10^{-6} \mathrm{~K}^{-1}\right)$, which is rather close to that of the underlying superalloy substrate (typically temperature dependent and in the range of $13-15 \times 10^{-6} \mathrm{~K}^{-1}$ [3] and therefore leads to moderate stresses during thermal cycling. However, a certain mismatch remains and typically relaxation at high temperature leads to increasing compressive stress levels in the coatings at low temperatures [4]. As a result, crack propagation and finally delamination of the coating is promoted. A tough ceramic is certainly helpful to suppress such early delamination. The highest toughness values in YSZ materials are found for low yttria contents ( 2 to 3 mol.\% $\mathrm{Y}_{2} \mathrm{O}_{3}$ ), leading by transformation toughening to extraordinary toughness values [5]. Unfortunately, this mechanism only operates at low temperatures and is also depending on a well-defined fine-grained microstructure. However, a high toughness is also observed in 4-5 mol.\% YSZ due to a ferroelastic switching [6] which is essential for a good performance of YSZ in TBC applications and one of the reasons why $4-5 \mathrm{YSZ}$ is the most frequently used TBC material.

A further improvement of the coating performance can be obtained by an optimization of the microstructure of the coatings mainly by reducing the stress levels and/or increasing the strain tolerance. This can be achieved by introducing porosity and cracks (inter-lamellar cracks, segmentation cracks etc.) or also columnar structures [7]. The most commonly used deposition technologies, thermal spray and electron beam - physical vapor deposition (EB-PVD), result in different types of coating microstructures. The deposition with EB-PVD typically leads to columnar structures with good thermo-mechanical performance [8]. This type of coating is typically used for the highly loaded parts as first stage blades in gas turbines. A large number of thermal barrier coatings are produced by thermal spray methods especially in stationary gas turbines and the coatings discussed here were prepared by this method, more specifically by the atmospheric plasma spraying (APS) process.

In the APS process, an electric arc generated between anode and cathode ionizes and heats the flowing process gases (argon, hydrogen, nitrogen or helium). Into this hot and fast plasma plume ceramic particles are injected, heated and accelerated. They then impinge on the substrate and form the coating. A recent more detailed description is given in [9]. As a result of the specific deposition process with its fast cooling a lamellar microstructure of flattened particles ("splats") with porosity and micro cracks is often found with 
porosity levels between about 10 and 25 percent. With more advanced thermal spray techniques as suspension plasma spraying (SPS) or plasma spray physical vapor deposition (PS-PVD) also columnar microstructures can be obtained [6].

Although YSZ appears to be an excellent TBC material, it shows some drawbacks especially with respect to high temperature stability. This fact led to an intense search for more than 2 decades for new thermal barrier coating materials with improved properties compared to the standard yttria stabilized zirconia (YSZ) [10], [11]. The new material should show no detrimental phase transformation at elevated temperature as YSZ does and it should have very low sintering rates at the foreseen operation temperatures beyond 1200 ${ }^{\circ} \mathrm{C}$. Different types of materials as perovskites, hexa-aluminates or pyrochlores have been considered as potential material. Among these materials especially gadolinium zirconate, a pyrochlore, seems to have a high potential and is meanwhile introduced in aero-engines [12]. Pyrochlores have a couple of promising properties as low thermal conductivity, high thermal expansion coefficients, low sintering rates, and good phase stability [6]. However, there are also some drawbacks, especially the low fracture toughness and the lower melting point compared to YSZ. The low toughness makes the use of double layer coatings with an intermediate YSZ layer essential [13].

To further improve the performance of TBC systems one has to understand the major degradation mechanisms. Certainly, one major factor is the growth of the thermally grown oxide (TGO) on the bond coat at elevated temperatures. This interlayer can reduce the bonding of the ceramic top coat to the bond coat and hence the substrate [14]. This can be described by the critical energy release rate $\mathrm{G}_{\mathrm{c}}$, which is reduced during operation. Once the elastic energy or the apparent energy release rate $G$ in the coating is sufficient to overcome $G_{c}$ the coating will spall-off. The elastic energy of the coating is dictated by the thermal expansion mismatch between substrate and topcoat, the temperature difference, the Young's modulus of the coating, and the thickness. During high temperature operation the porous ceramic top layers will start to sinter and by this increase the modulus and the elastic energy, promoting failure [15].

A commonly used method to investigate the performance of TBCs is the use of isothermal cycling. These tests give an insight in the typically TGO induced failure of the TBCs. However, a type of test more close to the realistic temperature profile in a gas turbine is a gradient test e.g. in a gas burner rig. This test will be used in the present study with a special focus on the influence of the surface temperature, which is often disregarded in the literature [16], [17]. A paper looking also on the influence of the surface temperature will be discussed later [18]. 


\section{Experimental}

The feedstock powders for the ceramic top coats were a commercially available agglomerated sintered 7YSZ Amperit powder (H.C. Starck Amperit 827.006, $d_{10}=54 \mu \mathrm{m}, d_{50}=80 \mu \mathrm{m}$, and $d_{90}=112 \mu \mathrm{m}$ ) and a spray dried Gadolinium Zirconate (GZO) powder with a hollow spherical morphology (H.C. Starck Amperit 835.090, $\left.d_{10}=60 \mu \mathrm{m}, d_{50}=83 \mu \mathrm{m}, d_{90}=117 \mu \mathrm{m}\right)$.

For thermal cycling, YSZ/GZO $(400 \mu \mathrm{m} / 200 \mu \mathrm{m})$ topcoats were deposited by APS in a Multicoat facility (Oerlikon Metco, Wohlen, Switzerland) with a three-cathode TriplexPro ${ }^{\mathrm{TM}} 210$ gun on Inconel 738 disk shaped substrates which had diameters of $30 \mathrm{~mm}$ and a thickness of $3 \mathrm{~mm}$. The outer edge of the substrates was machined in a radius of curvature of $1.5 \mathrm{~mm}$ to reduce the stress level and avoid failure at sharp edges. Before deposition of topcoats, the disk shaped substrates were coated with a $150 \mu \mathrm{m}$ NiCoCrAlY (Oerlikon Metco, Amdry 386) bondcoat by vacuum plasma spraying (VPS) in an Oerlikon Metco facility using a F4 gun. Mild steel substrates with an intermediate $\mathrm{NaCl}$ layer were coated with single layer YSZ and GZO for characterization especially for performing mercury of porosimetry on free-standing coatings.

The plasma jet was generated using $46 \mathrm{slpm}$ argon and $4 \mathrm{slpm}$ helium or hydrogen as process gas. The gun was moving with a meander type motion with a velocity of $500 \mathrm{~mm} / \mathrm{s}$ and a meander width of $2 \mathrm{~mm}$. For both YSZ and GZO the plasma current and the stand-off distance have been varied to investigate the influence of different microstructures on the thermal cyclic performance at high surface temperatures well above $1300{ }^{\circ} \mathrm{C}$. The processing conditions for GZO are partly taken from an earlier work [19]. The detailed process conditions for the samples used in the thermal cycling experiments are presented in Table 1. The short name of the coatings refer to the results of the porosimetry measurements given later. For the double layer coatings, the $400 \mu \mathrm{m}$ YSZ layer was applied using the YSZ dense conditions.

Gas burner test facilities operating with natural gas/oxygen mixture were used to evaluate the thermal cycling behavior of the systems [20]. The burner flame provides a homogeneous temperature distribution with a slight temperature decrease towards the outer rim of the specimen. This temperature decrease is typically about 50K, but might increase with increasing surface temperatures. At the same time, the back side of the substrate was cooled by compressed air to achieve the desired temperature gradient through the thermal barrier coating. 
During the test, surface temperature was measured with an infrared pyrometer. The emissivity of the coatings was assumed to be constant and the emissivity was determined to be close to 1 for YSZ. The same value was taken for the GZO.

The emissivity value of 1 is an approximation, more realistic values are about 0.98 [21] in the wave length range of the used pyrometer. For example, at object temperature of $1400^{\circ} \mathrm{C}$ the approximated value is leading to an underestimation of the surface temperature below $30 \mathrm{~K}$. On the other hand, emissions arising from the hot gas flame in the same spectral range lead to some increase of the pyrometer reading which, in part, counterbalance the effect of overestimated emissivity. As it appears difficult to precisely assess these competing effects, a simplified approach was made which give limited underestimation of the surface temperature.

Additionally, substrate temperature was measured by a thermocouple which was located in the center of the substrate. Three different surface temperatures were envisaged for testing, namely 1400, 1500, and $1550{ }^{\circ} \mathrm{C}$, while the substrate temperature was adjusted to about $1050{ }^{\circ} \mathrm{C}$. Due to slightly varying conditions, the mean values of logged temperature readings showed differences between the samples. Using the thermal conductivities of the coatings and the substrate, bond coat temperatures were calculated to be about $30 \mathrm{~K}$ to $40 \mathrm{~K}$ higher than the measured substrate temperatures. As the thermal conductivity change during cycling, a fixed approximate value of $1 \mathrm{~W} / \mathrm{m} / \mathrm{K}$ was assumed for the top coats. In fact, the lower conductivity of the GZO might lead to some overestimation of the bond coat temperature compared to YSZ.

After the thermal cycling mean substrate and surface temperatures during the heating phase were calculated by disregarding the temperature during the fast heating phase at the beginning of each cycle. In the test facility, after $5 \mathrm{~min}$ high temperature period, the burner was automatically removed and the surface was additionally cooled using compressed air during $2 \mathrm{~min}$ to achieve rapid cooling conditions. Cycling was stopped when a clearly visible spallation (about $20 \%$ of the surface area), or delamination of the coating occurred.

Metallographic cross sections have been prepared from all samples to investigate the microstructure and failure mode via SEM (Zeiss Ultra 55 FEG-SEM, Carl Zeiss Microscopy GmbH, Germany). Characterization of the coatings were also carried out using X-ray diffraction (Bruker-AXS/D4 Endeavor) for phase and 
crystallographic analysis and mercury intrusion porosimetry for pore size distribution (Pascal 140 and 440, Thermo Scientific, Hofheim, Germany).

Mechanical property measurements were performed on the metallographic cross sections of the samples in the as-sprayed and the cycled condition. The hardness and elastic modulus of top coats were measured with a depth-sensing micro-indentation test (H-100 Fischerscope, Helmut Fischer GmbH, Germany). The load applied on the indenter was set to be $1 \mathrm{~N}$. Effective Young's modulus was calculated from the initial unloading slope [22]. The elastic modulus of the materials can be obtained with the following equation:

$$
\mathrm{E}^{*}=\mathrm{E} / 1-v^{2}
$$

where $\mathrm{E}$ is the elastic modulus (GPa), $\mathrm{E}^{*}$ is effective Young's modulus (GPa), and $v$ is the Poisson's ratio; in this work, $v=0.22$ was adopted from [23]. In order to get reliable values, 15 indentations were performed on each sample at a distance of 80 to $90 \mu \mathrm{m}$ from the surface.

\section{Results and Discussion}

Microstructure

The as-sprayed microstructures of the four investigated thermal barrier coatings are shown in Figure 1. It should be mentioned here, that the YSZ porous coating used for the characterization of the as-sprayed condition was sprayed with a shorter meander size (150 instead of $200 \mathrm{~mm})$. In this specific case with low stand-off distance and rather high plasma gun power led to an increase of the substrate temperature to about $500{ }^{\circ} \mathrm{C}$ and also to a higher deposition efficiency (750 $\mu \mathrm{m}$ coating thickness instead of $\left.600 \mu \mathrm{m}\right)$.

The mercury porosimetry results are shown in Figure 2. It shows the typical size distributions of thermally sprayed ceramic coatings consisting of fine pores (micro cracks) and large (globular) pores. Due to the fact that the larger pores are also often filled via the fine cracks the distributions are shifted towards fine pore sizes. As a result, the distributions due hardly reflect the amount of larger pores in the high porosity coatings as seen in Figure 1. With the short stand-off distance a considerable higher porosity level of about $23 \%$ could be reached for YSZ, however, on the expense of reduced deposition efficiency (s. Table 1). It is assumed, that the short stand-off distance allows only melting of the surface of the particles and so the high viscous (rather cold) core of the particles is not able to deform easily during impact leading to increased 
porosity. The longer stand-off distance led to a porosity of about $15 \%$ for the YSZ. In the case of GZO an investigation on the influence of spraying conditions on porosity and efficiency have been made (not shown here) before the selection of the short stand-off distance. The selected parameters of GZO dense given in Table 1 gave a good deposition efficiency and a rather high porosity level of more than $15 \%$ measured by digital image analysis on SEM images of free-standing coatings. However, the more reliable mercury porosimetry reveals a quite low porosity level (11.2\%). In order to increase the porosity, an extremely large stand-off distance for GZO was chosen, which led to an in-flight solidification of the particles and a moderate porosity level of $13.8 \%$. It can be stated that the establishment of a rather high porosity levels is more difficult for GZO than for YSZ. The reason is not fully clear as the melting point compared to YSZ is not much lower [24]. Two reasons may play a role, the rather low heat capacity of GZO which accelerates the heating of the particles [25] or the (slightly) reduced high temperature viscosity which leads to better deformation during splat formation and hence lower porosity [26].

\section{Thermal cycling results}

In Figure 3 the cycles to failure as a function of the surface temperature are given. There is for all samples a clear tendency of a reduced lifetime with increased surface temperature. However, it has to be considered that it was not possible to keep the bond coat temperature exactly constant. Instead, it was found that the bond coat temperatures varied between 1068 and $1108^{\circ} \mathrm{C}$ with the relation that higher surface temperatures also led to somewhat higher bond coat temperatures. This was due to the fact that the substrate temperature was kept constant which leads to higher bond coat temperatures with increased surface temperatures. Additionally, in the burner rigs always some fluctuation of the heat load during the tests is observed which leads to additional variations.

For an approximate compensation of this effect, the lifetime normalized to $1100^{\circ} \mathrm{C}$ bond coat temperature was calculated assuming an activation energy of $3.67 \mathrm{eV}$ for the different thermally activated processes leading to degradation (as oxidation, sintering). This activation energy corresponds to an increase of lifetime by a factor of 2 when reducing the temperature by $30 \mathrm{~K}$ from $1100{ }^{\circ} \mathrm{C}$ (see [13]). 
Although not shown here the normalization does not change Figure 3 significantly, only the GZO porous layer is now at intermediate and highest temperatures the best performing coating. Figure 4 shows the images of the samples after thermal cycling. There is a tendency of failure within the ceramic layer for both dense systems at higher temperatures (see first and third row). That is especially true for the GZO dense system, where obviously the GZO top layer spalled off at the high surface temperature (Figure 4 third row, middle and right), and to some extent for the dense YSZ systems loaded at high temperatures. For the other systems the failure occurs close to the interface $\mathrm{TBC} /$ bond coat which is an indication that the growth of the thermally grown oxide (TGO) plays a major role for the failure.

In Figure 5 SEM micrographs of the cycled samples from the central regions are shown. Between the porous ceramic topcoats and the bond coat layers a dark intermediate layer, the TGO, is clearly found which is varying in thickness according to the different exposure times at temperature. As was observed earlier ([27], [28]) it is consisting mainly of an alumina-based scale with some yttrium aluminate inclusions. As the same bond coat and similar bond coat temperatures were used throughout the tests, it is not surprising that the TGO growth is similar for all the tested samples and hence, has a similar effect on the degradation for all systems. The typical failure mode in our burner rigs is a combination of oxidation (TGO) driven degradation and thermal cyclic/fatigue degradation. This is similar to the loading in gas turbines with the difference, that some components like blades additionally see a large mechanical load in a gas turbine.

\section{TGO induced failure in a thermal gradient}

In order to gain an understanding of the failure mechanisms of the investigated TBC systems, existing descriptions of the failure of such systems will be described briefly. According to Öchsner [29], failure especially crack propagation at the interface (delamination) takes place in a TBC if the apparent energy release rate $\mathrm{G}$ is larger than the critical one $\mathrm{G}_{\text {crit. }}$ The apparent energy release rate (so the energy available 
for crack propagation in the coating) of a TBC system in a thermal gradient can be calculated in the case of a crack much longer than the coating thickness:

$$
G=\frac{\bar{\sigma}^{2} h}{2 E_{c}}\left(1+\frac{1}{12}\left(\frac{\sigma_{s}-\sigma_{i}}{\bar{\sigma}}\right)^{2}\right)
$$

with $\mathrm{h}$ and $\mathrm{E}_{\mathrm{c}}$ thickness and Young's modulus of the coating, respectively; $\sigma_{\mathrm{s}}$ and $\sigma_{\mathrm{i}}$ in plane stress in the coating at the surface and at the interface (plain stress state assumed), respectively; and the mean stress $\bar{\sigma}=$ $\left(\sigma_{\mathrm{s}}+\sigma_{\mathrm{i}}\right) / 2$. Assuming that at high temperatures the stresses relax quite fast, compressive stresses will be build up in the coating during cooling. The stress level and also the energy release rate at room temperature will be reduced for higher surface temperatures at constant substrate temperatures (i.e. larger gradient) as the additional thermal strain due to the higher temperature in the coatings partly compensates the misfit of thermal expansion between coating and substrate.

Assuming a Young's modulus of $20 \mathrm{GPa}$ the energy release rate can be estimated, ranging from about 205 $\mathrm{J} / \mathrm{m}^{2}$ for isothermal testing down to $105 \mathrm{~J} / \mathrm{m}^{2}$ at $1400{ }^{\circ} \mathrm{C}, 85 \mathrm{~J} / \mathrm{m}^{2}$ at $1500{ }^{\circ} \mathrm{C}$ and $77 \mathrm{~J} / \mathrm{m}^{2}$ at $1550{ }^{\circ} \mathrm{C}$ surface temperature. As a result, this simple approach cannot explain the reduced lifetime at higher surface temperatures as there is less elastic energy for crack propagation available at high temperatures due to the gradient.

\section{Influence of Sintering}

One relevant factor which was ignored up to now is the change of the Young's modulus during cycling. As in equation (1) the mean stress is proportional to the Young's modulus, the energy release rate is also proportional to it, a stiffer coating can supply more elastic energy for crack propagation. To have a better insight into the development of the Young's modulus during thermal cycling, the stiffness of the coatings in a surface near region has been analyzed by an indentation technique. The results of the measurements are presented in Figure 6a. First of all, it has to be stated that indentation stiffness values are typically much higher than elastic modulus results obtained from macroscopic testing as bending tests. The reason is the sampling of rather small regions, so large pores and cracks which largely reduce the apparent modulus of 
the coatings are not taken into account. On the other hand, the indentation measurements certainly give an indication of the sintering in the coating microstructure which will be related to the overall modulus.

Figure 6a shows for both dense materials, as expected, higher stiffness values (filled symbols) for the dense coatings. Furthermore, the results after tests at $1400{ }^{\circ} \mathrm{C}$ reveal for dense YSZ a considerable increase of Young's modulus compared to the as-sprayed condition. For the GZO this is not clearly visible, especially not for the porous GZO. This might be an indication of the higher sintering resistance of GZO. In order to consider the time at temperature, the stiffness data are also plotted as a function of the Larson Miller parameter $\mathrm{LMP}=\mathrm{T}[\mathrm{K}](30+\log (\mathrm{t}[\mathrm{h}]))([30])$ in Figure $6 \mathrm{~b}$. For the dense $\mathrm{YSZ}$ clearly stiffness decreases with higher cycling time and temperature. As was observed earlier, in cyclic loading one can have competitive processes of sintering and crack formation/growth. It is assumed that especially the fast initial cooling rates and the accompanied tensile stress in the coating can promote crack formation [31]. As a result, in most of the coatings in Fig. 5 segmentation cracks running from the surface into the coating can be found. In summary, sintering does not appear to play a major role for the faster degradation of the TBCs at higher temperatures.

\section{Phase transformation}

An additional reason for micro cracking or even delamination of the YSZ coatings might be the phase changes from tetragonal prime $\left(\mathrm{t}^{\prime}\right)$ to tetragonal $(\mathrm{t})$ and then to monoclinic $(\mathrm{m})$ during cooling, a wellknown process observed in YSZ TBCs [32]. An analysis can be made by XRD. It should be emphasized here that XRD only give information on the first $10-30 \mu \mathrm{m}$ of the coatings, so in our case of gradient testing the part of the coating seeing the highest temperatures.

XRD patterns revealed mainly a $t^{\prime}$ - structure of the YSZ coatings after spraying with about $1-2 \%$ monoclinic phase (Fig.7). After cycling the amount of $t^{\prime}$ phase was reduced and significant amounts of cubic and tetragonal phases appear indicating the start of a phase transformation, however the amount of monoclinic phase remained rather small $(2-3 \%)$. The porous YSZ TBCs did not show a pronounced 
decrease in Young's modulus (s. Fig. 6). If cracking is mainly related to the phase transition, a possible explanation can be the large pore volume available in these coatings, which might be beneficial for a compensation of the large volume increase due to the $t$ to $m$ transformation during cooling. In summary, the amount of phase transformation to monoclinic is very limited in the YSZ systems and the accompanying strain can hardly explain the early failure at higher temperature.

As shown before in the GZO double layers it was observed that the GZO is present in the defect fluorite structure after spaying and will form the ordered pyrochlore structure during annealing [13]. This transformation is not accompanied with large volume changes and hence, seems not to introduce detrimental stress levels in the coatings. Interestingly, the samples tested at about $1550{ }^{\circ} \mathrm{C}$ did again show the defect fluorite structure. The explanation is the stability range of the pyrochlore phase [33]. Above about $1500{ }^{\circ} \mathrm{C}$ the pyrochlore transforms into defect fluorite, the fast cooling then prevents the reordering and the defect fluorite phase remains.

To sum up the phases changes in the pyrochlore are not the reason for early failure of the double layer systems.

\section{Influence of porosity levels}

For the YSZ coatings the question remains, why the lifetime of the porous $\mathrm{TBC}$ s is equal or at $1500{ }^{\circ} \mathrm{C}$ even lower than those of the dense YSZ TBCs (Figure 3) although their Young's modulus is lower. Since the early work of Stecura it is known that porosity certainly is advantageous at least in definite ranges [34], he found a maximum thermal cyclic life for about $15 \%$ porosity. For the discussion of an optimal porosity level one should have in mind that with reducing the Young's modulus and hence the strain energy (energy release rate) also the toughness is typically reduced [35]. In models describing the fracture of ceramics the crack growth velocity is depending on the ratio of stress intensity (which is proportional to stress level and hence Young's modulus) to fracture toughness. Of course, the stress intensity is depending on the actual 
loading conditions, however, in thermal loading the strain is similar for coatings with different porosity levels (TEC is hardly depending on porosity), so the stress is governed by the Youngs'modulus.

The ratio between stress intensity and fracture toughness is at least for sintering ceramics not depending too much on microstructure and porosity level [36], however, this might not be true for plasma-sprayed coatings with their specific microstructure. In addition, if the energy release rate of the coatings due to the high Young's modulus become too high, it might exceed the critical energy release rate of the TGO/topcoat interphase and so the crack will run mainly at or through the TGO and not through the YSZ topcoat giving earlier failure. Also it was observed in APS sprayed YSZ coatings that toughness decreased with aging even at $1100{ }^{\circ} \mathrm{C}$ although Young's modulus increased [37,38]. This effect would lead to an accelerated degradation of the coatings. It might also be possible that the more pronounced phase transformation of the porous YSZ into the low toughness cubic phase found at lower temperatures (s. Figure 7) plays a role.

So, the complex interplay of sintering, micro cracking, and phase transformation depending on the type of thermal load and the microstructure might be a reason for the similar behavior of dense and porous YSZ coatings. It should also be stated that at certain porosity levels stress is still build-up under compressive load due to interlocking of the sprayed splats, the limited bonding between these splats will lead to fast crack growth. As a further remark, the giving argumentation is only valid for the specific microstructure of thermally sprayed coatings, in other coatings as EB-PVD coatings certainly other strategies for optimization are necessary.

Interestingly, the effect of porosity in the GZO/YSZ system is in the investigated regime much more pronounced probably because the dense GZO has a very low porosity level considerably lower than for the YSZ. The good performance of the GZO layer with higher porosity might be related to lower sintering.

\section{Influence of large thermal gradients}

So, still a plausible explanation for the reduced lifetime at elevated temperatures is missing. Hutchinson and Evans discussed the influence of a gradient on the failure of TBC systems [39]. They stated that a gas burner will not give sufficiently high heat fluxes, but their results should be discussed here as our rigs give 
heat fluxes of nearly $1 \mathrm{MW} / \mathrm{m}^{2}$ close to the highest flux in gas turbines. They distinguish between sintering induced cracks or those arising from large cracks within the TBC or from edges. Cracks seem to start from edges (see Fig. 4), so the latter mechanism might be suitable. However, the calculations assume a linear elastic approach which gives then a moment due to the stress involved with the gradient. Earlier calculations show that the stresses relax rather fast at elevated temperatures [13] and hence, the driving force is missing. In addition, the failure should occur at high temperature that was not found in the present investigation for most of the samples.

In a paper [18] the reduction of the lifetime with increasing surface temperature was explained by the approach described above using a large interphase crack, however, as stated above high temperature stress levels are probably fast relaxed and can therefore hardly explain failure.

\section{Influence of cooling transient}

Another important feature of our burner rigs (and also of gas turbines!) are the fast heating and cooling rates, due to the surface cooling with compressed air and the radiation cooling initial cooling rates above 200K/s can be obtained. These transient temperature distributions can lead to an additional driving force for cracking which was intensively discussed in literature [40,41]. As expected the energy release rate is determined by the cooling rate. Jackson used an exponential temperature drop and found that depending on the properties of the TBC system the energy release rate due to the transient cooling exceeded the one of slow cooling after some seconds of cooling. In these calculations typically convective cooling is considered as cooling mechanism. Due to the very high surface temperatures in our case also radiation cooling (proportional to $\mathrm{T}^{4}$ ) will play an important role. Assuming black body radiation about $0.6 \mathrm{MW} / \mathrm{m}^{2}$ cooling power will result at $1550{ }^{\circ} \mathrm{C}$. In addition, also the convection cooling (proportional to $\mathrm{T}_{\text {surface }}-\mathrm{T}_{\text {cooling gas }}$ ) will be improved due to the higher surface temperature. Although this argumentation appears reasonable, an experimental verification is needed. As described earlier the cooling in our burner rig is improved by cooling air impinging on the surface of our TBC samples. This cooling air can be switched off to reduce the cooling to some degree. This was done for the dense samples still available from the same production 
run (2 YSZ and $1 \mathrm{GZO/YSZ} \mathrm{sample,} \mathrm{all} \mathrm{dense} \mathrm{variants).} \mathrm{The} \mathrm{results} \mathrm{are} \mathrm{given} \mathrm{in} \mathrm{Table} \mathrm{2.} \mathrm{At} \mathrm{least} \mathrm{for} \mathrm{sample}$ YSZ A a considerable improvement is obvious, which is a hint that the cooling rates and the proposed mechanism play an important role. Also for the GZO/YSZ sample a prolongation of the lifetime was observed, although it is still very limited. Here probably the low toughness plays the dominant role.

In order to get a better insight into the failure during transient thermal gradient testing a simplified model to describe this mechanism was developed. In Fig. 8 some basic assumptions are illustrated.

It is assumed that after removing the burner rig the cooling flux $\mathrm{j}_{\mathrm{Q}}$ keeps constant. For a thick substrate with thickness $d_{\text {sub }}$ it is mainly used to cool down the substrate, which can be approximately calculated at a time t by eq. (2):

$$
j_{Q}=-c_{v s u b} \rho_{s u b} \frac{d T_{s u b}}{d t}
$$

with $\mathrm{c}_{\mathrm{vsub}}$ and $\rho_{\text {sub }}$ the specific heat and density of the substrate.

(3) can be solved with $\mathrm{T}_{\text {sub }}(0)=\mathrm{T}_{\text {sub0 }}$

$$
T_{\text {sub }}=T_{\text {sub } 0}-\frac{j_{Q}}{c_{v s u b} \rho_{\text {sub }} d_{\text {sub }}} t
$$

In the coating it is assumed that the thermal diffusion effects only a thickness equal to the diffusion length $\mathrm{d}_{\text {diffusion }}$ which can be written as:

$$
d_{\text {diffusion }}=\sqrt{\pi D t}
$$

with $\mathrm{D}=\lambda_{\mathrm{c}} /\left(\mathrm{c}_{\mathrm{vc}} \rho_{\mathrm{c}}\right)$ being the diffusion coefficient, $\lambda_{\mathrm{c}}, \mathrm{c}_{\mathrm{vc}}$ and $\rho_{\mathrm{c}}$ are the thermal conductivity, the specific heat and the density of the coating. The factor $\pi^{1 / 2}$ was added as the initial slope of the temperature profile, the diffusion length than corresponds to the exact solution [42].

The temperature drop at the surface after the start of the cooling phase is estimated by

$$
j_{Q}=-\lambda_{c} \frac{T_{\text {coating }}(t)-T_{\text {coating } 0}}{d_{\text {diffusion }}}
$$


We assume a linear temperature profile as shown in Fig. 8. From the temperature profile the thermal strain can be calculated using the thermal expansion coefficient $\alpha_{c}$ assuming a stress free state at the end of the heating phase. In addition, the substrate cooling as calculated in (4) using the thermal expansion coefficient $\alpha_{\text {sub }}$ of the substrate lead to a substrate strain which reduces the strain in the coating. With the strain distribution in the coating the forces per depth $\mathrm{P}$ and the moment per depth $\mathrm{M}$

$P=\int_{0}^{d_{c}} \sigma(x) d x$ and $M=\int_{0}^{d_{c}} \sigma(x)\left(x-\frac{d_{c}}{2}\right) d x$

according to [43] can be calculated for plain stress. This is then used to calculate the energy release rate for thick substrates:

$$
G=\frac{1}{2 E_{c_{C}}}\left(\frac{P(t)^{2}}{d_{c}}+12 \frac{M(t)^{2}}{d_{c}^{3}}\right)
$$

with $d_{c}$ the coating thickness. The calculation shows that the maximum in the energy release rate is reached when the diffusion length is close to the coating thickness $d_{c}$. Using this the maximum of the energy release rate can be calculated:

$$
G_{\text {max }}=\frac{E_{c} d_{c}}{2}\left\{\left(\frac{\alpha_{c}}{2} \frac{1}{1+\beta}\left(\Delta T_{\text {grad }}+\beta \Delta T_{\text {max }}\right)-\frac{c_{v c} \rho_{c} d_{c}}{c_{v s u b} \rho_{\text {sub }} d_{\text {sub }}} \frac{\alpha_{\text {sub }}}{\pi} \Delta T_{\text {grad }}\right)^{2}+\frac{1}{12}\left(\alpha _ { c } \frac { 1 } { 1 + \beta } \left(\Delta T_{\text {grad }}+\right.\right.\right.
$$

$\left.\left.\left.\beta \Delta T_{\max }\right)\right)^{2}\right\}$

with $\Delta \mathrm{T}_{\text {grad }}$ the thermal gradient across the TBC, $\Delta \mathrm{T}_{\max }$ the temperature difference between surface temperature and room temperature (RT), $\beta=\alpha \mathrm{d}_{\mathrm{c}} / \lambda_{\mathrm{c}}$ and $\alpha$ being the heat transfer coefficient (determined from $\left.\alpha=\left(\lambda_{c} \Delta T_{\text {grad }} / \mathrm{d}_{c}\right) /\left(T_{\text {sub }}-\mathrm{RT}\right)\right)$. For the calculation data from [13] have been used.

The calculated values at $1400{ }^{\circ} \mathrm{C}, 1500{ }^{\circ} \mathrm{C}$ and $1550{ }^{\circ} \mathrm{C}$ are plotted in Figure 9 as a function of the mean time at these temperatures for all the YSZ samples (porous and dense). Note that the longest time correspond to the lowest surface temperature. In addition, the critical energy release rate in the as-sprayed system as given in [44] is added at $0 \mathrm{~h}$. Furthermore, the values given above for a gradient testing according to equation (2) are shown. It follows from Figure 9 that the energy release rate due to the transient cooling exceeds the one from the cooling from a gradient above $1400^{\circ} \mathrm{C}$. The maximum of the energy release rate 
will promote failure if it is equal to the critical energy release rate and, although slight variations are found, these maximum values are reduced with time. The decrease in the critical energy release rate with time is typically explained by the increasing damage at the interphase with increasing cycle numbers [13]. Although we did not measure the critical energy release rates the suggested behavior given in Figure 9 can serve as a consistent explanation of the reduced lifetime at elevated temperatures due to the effect of the transient loading. In addition, the formula given in (8) allows an approximation of the energy release rate during transient cooling depending on the different properties of the coating systems. This might be useful for the comparison and optimization of such systems and will be probably more important in the future due to the increased use of load-flexible gas turbines operating at extremely high hot gas temperatures.

\section{Conclusions}

The performance of YSZ single and GZO/YSZ double layer TBCs were evaluated in a burner rig at very high surface temperatures up to $1550^{\circ} \mathrm{C}$. Dense GZO/YSZ coatings performed badly at high temperatures, while porous layers showed the best high temperature results. Both porous and dense YSZ coatings performed well even at highest temperature only with somewhat lower lifetimes than porous GZO/YSZ systems. As possible failure mechanisms sintering and phase transformations have been discussed with the conclusion that they are not dominant, in some cases sintering seems to be compensated by micro cracking. As a major degradation mechanism at the elevated temperatures the transient cooling was identified. A simplified model calculating energy release rates for these loading condition was described. It could be shown that under certain conditions the transients will lead to high energy release rates shortly after the start of the cooling. With increasing surface temperatures the energy release rate during transient cooling is increased leading to earlier failure of the coatings.

\section{Acknowledgements}

The authors would like to thank Mr. F. Kurze and Mr. R. Laufs for performing the plasma spraying experiments, Mr. M. Tandler for carrying out the thermal cycling tests, and Dr. J. Malzbender (IEK-2) for 
supporting the indentation tests. Also the authors gratefully acknowledge the financial support of the

German Research Foundation (DFG) through project no. VA 163/5-2.

\section{References}

1. S. Stecura, Two-Layer Thermal Barrier Coating for High temperature Components, Am. Ceram. Soc. Bull., 1082-1085 (1978)

2. L.F.J. D.P.H. Hasselman, L.D. Bentsen, S. Rahmatullah, L.L. Hong, M.V. Swain, Thermal Diffusivity and Conductivity of Dense Polycrystalline ZrO2 Ceramics: a Survey, Am. Ceram. Soc. Bull., 66, 799806 (1987)

3. X.Q. Cao, R. Vaßen, D. Stöver, Ceramic materials for thermal barrier coatings, J. Eur. Ceram. Soc., 24, 1 - 10 (2004) (in eng)

4. M. Ahrens, R. Lampenscherf, R. Vaßen, D. Stöver, Sintering and creep processes in plasma-sprayed thermal barrier coatings, J. Therm. Spray Technol., 13, 432 - 442 (2004) (in eng)

5. C.G. Andersson, TK Temperature-dependance of transformation toughening in a ZrO2 system theory, Am. Ceram. Soc. Bull., 58(3), 338-338 (1979)

6. A.V. Virkar, R.L.K. Matsumoto, Ferroelastic Domain Switching as a Toughening Mechanism in Tetragonal Zirconia, J. Am. Ceram. Soc., 69(10), C-224-C-226 (1986)

7. E. Bakan, R. Vassen, Ceramic Top Coats of Plasma-Sprayed Thermal Barrier Coatings: Materials, Processes, an Properties, J. Therm. Spray Technol., 26(6), 992 - 1010 (2017)

8. A. Feuerstein, J. Knapp, T. Taylor, A. Ashary, A. Bolcavage, N. Hitchman, Technical and Economical Aspects of Current Thermal Barrier Coating Systems for Gas Turbine Engines by Thermal Spray and EBPVD: A Review, J. Therm. Spray Technol., 17(2), 199-213 (2008)

9. M. Mutter, G. Mauer, R. Mücke, O. Guillon, R. Vassen, Correlation of splat morphologies with porosity and residual stress in plasma-sprayed YSZ coatings, Surf. Coat. Technol., 318, 157 - 169 (2017)

10. R. Vaßen, X. Cao, F. Tietz, D. Basu, D. Stöver, Zirconates as new materials for thermal barrier coatings, J. Am. Ceram. Soc., 83, 2023 (2000) (in eng)

11. D.R. Clarke, M. Oechsner, N.P. Padture, Thermal-barrier coatings for more efficient gas-turbine engines, MRS Bull., 37(10), 891-898 (2012)

12. C.G. Levi, J.W. Hutchinson, M.-H. Vidal-Setif, C.A. Johnson, Environmental degradation of thermalbarrier coatings by molten deposits, MRS Bull., 37(10), 932-941 (2012)

13. R. Vaßen, F. Träger, D. Stöver, New Thermal Barrier Coatings Based on Pyrochlore/YSZ DoubleLayer Systems, Int. J. Appl. Ceram. Tec., 1(4), 351-361 (2004)

14. R. Vaßen, S. Giesen, D. Stöver, Lifetime of Plasma-Sprayed Thermal Barrier Coatings: Comparison of Numerical and Experimental Results, J. Therm. Spray Technol., 18(5-6), 835-845 (2009)

15. J.W. Hutchinson, M.R. Begley, The mechanics and reliability of films, multilayers and coatings, Cambridge University Press, 2017

16. F. Traeger, R. Vaßen, K.H. Rauwald, D. Stöver, Thermal Cycling Setup for Testing Thermal Barrier Coatings, Adv. Eng. Mater., 5(6), 429-432 (2003)

17. C.-J. Li, H. Dong, H. Ding, G.-J. Yang, C.-X. Li, The Correlation of the TBC Lifetimes in Burner Cycling Test with Thermal Gradient and Furnace Isothermal Cycling Test by TGO Effects, J. Therm. Spray Technol., 26(3), 378-387 (2017) 
18. H. Dong, G.-J. Yang, H.-N. Cai, H. Ding, C.-X. Li, C.-J. Li, The influence of temperature gradient across YSZ on thermal cyclic lifetime of plasma-sprayed thermal barrier coatings, Ceram. Int., 41(9, Part A), 11046-11056 (2015)

19. E. Bakan, D.E. Mack, G. Mauer, R. Mücke, R. Vaßen, Porosity-Property Relationships of PlasmaSprayed Gd2Zr207/YSZ Thermal Barrier Coatings, J. Am. Ceram. Soc., 98(8), 2647-2654 (2015)

20. F. Traeger, R. Vaßen, K.-H. Rauwald, D. Stöver, Thermal cycling setup for testing thermal barrier coatings, Adv. Eng. Mater., 5, 429 - 432 (2003) (in eng)

21. C.M.S. J.I. Eldridge, K.W. Street, Infrared radiative properties of yttria-stabilized zirconia thermal barrier coatings, Ceramic Engineering \& Science Proceedings, 23(4), 417-430 (2002)

22. W.C. Oliver, G.M. Pharr, An improved technique for determining hardness and elastic modulus using load and displacement sensing indentation experiments, Journal of materials research, 7(06), 1564-1583 (1992)

23. S.R. Choi, D. Zhu, R.A. Miller, Mechanical Properties/Database of Plasma - Sprayed ZrO2 - 8wt\% Y2O3 Thermal Barrier Coatings, International Journal of Applied Ceramic Technology, 1(4), 330342 (2004)

24. R.M. Leckie, S. Krämer, M. Rühle, C.G. Levi, Thermochemical compatibility between alumina and $\mathrm{ZrO}_{2}-\mathrm{GdO}_{3 / 2}$ thermal barrier coatings, Acta Mater., 53(11), 3281-3292 (2005)

25. H. Lehmann, D. Pitzer, G. Pracht, R. Vassen, D. Stöver, Thermal Conductivity and Thermal Expansion Coefficients of the Lanthanum Rare-Earth-Element Zirconate System, J. Am. Ceram. Soc., 86(8), 1338-1344 (2003)

26. E. Bakan, D.E. Mack, G. Mauer, R. Vassen, A Double Layer Thermal Barrier Concept made of Gadolinium Zirconate and YSZ, International Thermal Spray Conference and Expositioned., 2015

27. R.V. J. Toscano, A. Gil, M. Subanovic, D. Naumenko, L. Singheiser, W.J. Quadakkers, Parameters affecting TGO growth and adherence on MCrAlY-bond coats for TBC's, Surf. Coat. Technol., 201, 3906-3910 (2006)

28. R. Vaßen, S. Giesen, D. Stoever, Lifetime of Plasma-Sprayed Thermal Barrier Coatings: Comparison of Numerical and Experimental Results, J. Therm. Spray Technol., 18, 835-845 (2009) (in eng)

29. M. Öchsner, "Ein Beitrag zur Lebensdauervorhersage von keramischen Wärmedämmschichten," 2001

30. J.M. F. R. Larson, Transactions of the ASME, July, 765-775 (1952)

31. A.M. Limarga, R. Vaßen, D.R. Clarke, Stress Distributions in Plasma-Sprayed Thermal Barrier Coatings Under Thermal Cycling in a Temperature Gradient, Journal of applied mechanics, 78, 1 9 (2011) (in eng)

32. J.L.S. R.A. Miller, R.G. Garlick, Phase Stability in Plasma-Sprayed Partially Stabilized Zirconia-Yttria, The American Ceramic Society, Columbus, OH, 1981

33. O.F.a.H.J. Seifert, Up-Date of a Thermodynamic Database of the ZrO2-Gd2O3-Y2O3-Al2O3 System for TBC Applications, Journal of Phase Equilibria and Diffusion 32(1), 2-16 (2011)

34. S. Stecura, Optimization of the NiCrAl-Y/ZrO2-Y203 Thermal Barrier System, ed., NASA Technical Memorandum 86905, 1985

35. T.F. D. Munz, Ceramics, Mechanical Properties, Failure Behaviour, Materials Selection, Springer, 1999

36. D. Jauffrès, C.L. Martin, R.K. Bordia, Design of strain tolerant porous microstructures - A case for controlled imperfection, Acta Mater., 148, 193-201 (2018)

37. J.D. Osorio, D. Maya, A.C. Barrios, A. Lopera, F. Jiménez, J.M. Meza, J.P. Hernández-Ortiz, A. Toro, Correlations Between Microstructure and Mechanical Properties of Air Plasma-Sprayed Thermal Barrier Coatings Exposed to a High Temperature, J. Am. Ceram. Soc., 96(12), 3901-3907 (2013) 
38. C.C. Li, T. Wang, X.J. Liu, Z.H. Zheng, Q. Li, Evolution of mechanical properties of thermal barrier coatings subjected to thermal exposure by instrumented indentation testing, Ceram. Int., 42(8), $10242-10250$ (2016)

39. J.E. Hutchinson, AG, On the delamination of thermal barrier coatings in a thermal gradient, Surface \& Coating Technology, 149( 2-3), 179-184

40. R.W. Jackson, M.R. Begley, Critical cooling rates to avoid transient-driven cracking in thermal barrier coating (TBC) systems, International Journal of Solids and Structures, 51(6), 1364-1374 (2014)

41. S. Sundaram, D.M. Lipkin, C.A. Johnson, J.W. Hutchinson, The Influence of Transient Thermal Gradients and Substrate Constraint on Delamination of Thermal Barrier Coatings, Journal of Applied Mechanics, 80(1), 011002-011002-011013 (2012)

42. J.H.W. B. A. Boley, Theory of thermal stresses, John Wiley \& Sons Inc, 1960

43. M.R. Begley, Hutchinson, J.W., The mechanics and reliability of films, multilayers and coatings, Cambridge University Pres, 2017

44. M. Frommherz, A. Scholz, M. Oechsner, E. Bakan, R. Vassen, Gadolinium zirconate/YSZ thermal barrier coatings: Mixed-mode interfacial fracture toughness and sintering behavior, Surf. Coat. Technol., 286, 119 - 128 (2016)

\section{Figure captions}

Figure 1 SEM images of the as-sprayed condition of the four investigated systems (s. Table 1), a) YSZ dense, b) YSZ porous, c) GZO dense, d) GZO porous.

Figure 2 Mercury porosimetry results of the two used YSZ layers and the two GZO layers used in the double layer coatings (s. Table1).

Figure 3 Cycles to failure as a function of surface temperature for the four different $\mathrm{TBC}$ systems given in Table 1.

Figure 4 Images of the cycled samples, first row YSZ dense, second row YSZ porous, third row GZO dense, fourth row GZO porous, left column: low surface temperature $\left(\sim 1400^{\circ} \mathrm{C}\right)$, middle column: intermediate temperature $\left(\sim 1500^{\circ} \mathrm{C}\right)$, right column: high temperature $\left(\sim 1550^{\circ} \mathrm{C}\right)$. 
Figure 5 SEM micrographs of the cycled samples, first row YSZ dense, second row YSZ porous, third row GZO dense, fourth row GZO porous, left column: low surface temperature $\left(\sim 1400^{\circ} \mathrm{C}\right)$, middle column: intermediate temperature $\left(\sim 1500^{\circ} \mathrm{C}\right)$, right column: high temperature $\left(\sim 1550^{\circ} \mathrm{C}\right)$.

Figure 6 Indentation stiffness for as-sprayed and cycled samples as a function of testing temperature (room temperature values represent as-sprayed condition, a), and as function of the Larson Miller parameter (b).

Figure 7 Results of phase analysis from XRD patterns at the surface of dense and porous YSZ samples cycled in the burner rig at the indicated temperatures ( 25 corresponds to as-sprayed).

Figure 8 Schematic of the temperature profile in the TBC system during transient cooling phase used in the calculations.

Figure 9 Energy release rate as calculated from equation (8), closed symbols, and according to equation (2) (open symbols) at the corresponding mean surface temperatures as a function of the mean time at temperature i.e. the mean lifetime of all samples tested at the corresponding temperature. The value at zero time is the value for the as-sprayed coatings given in [41]. 


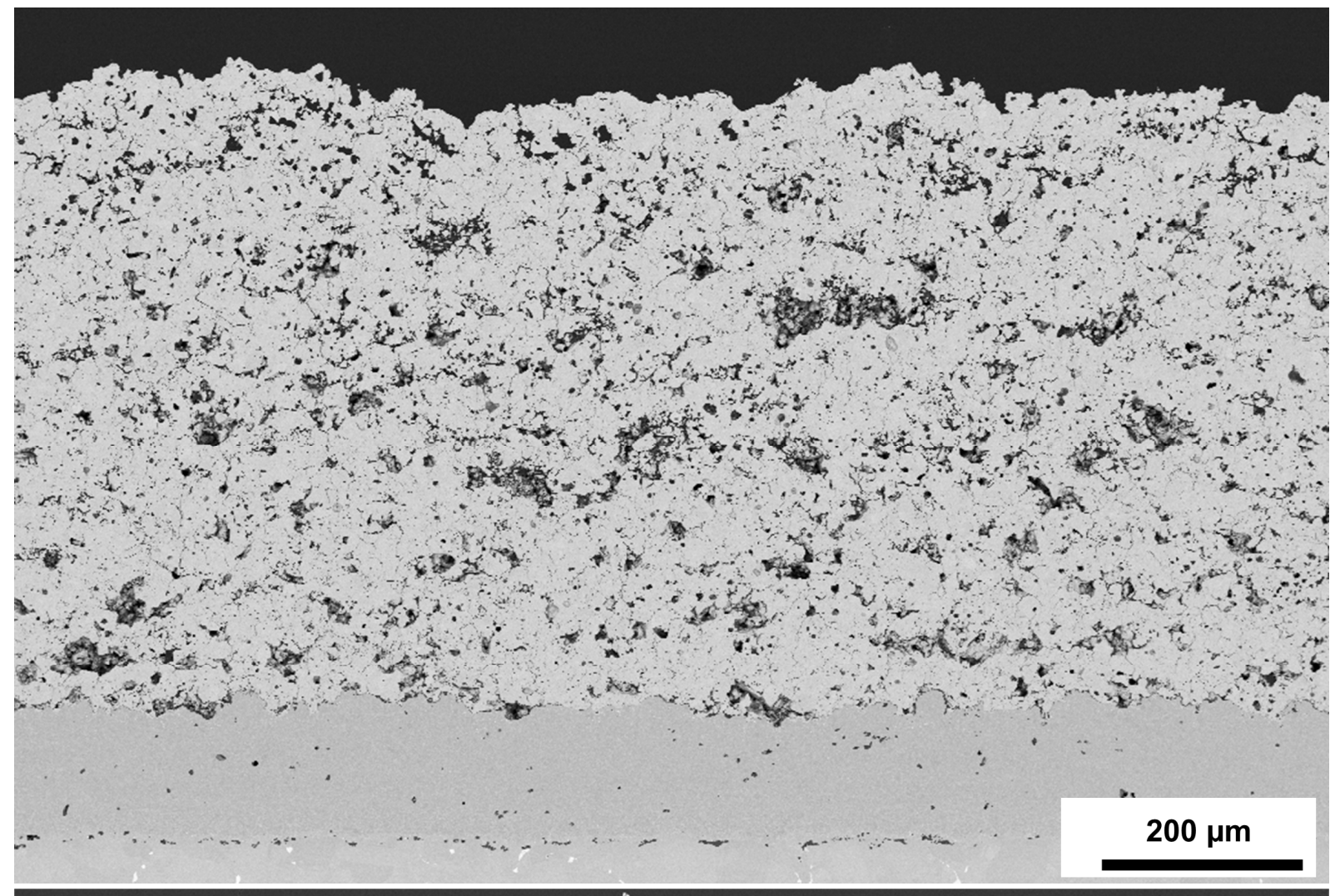

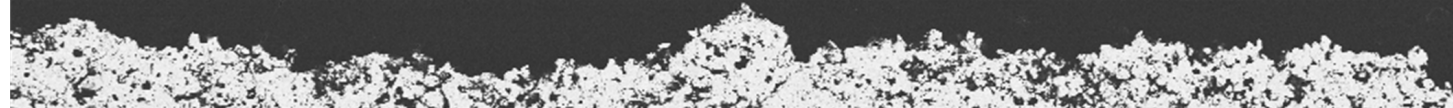

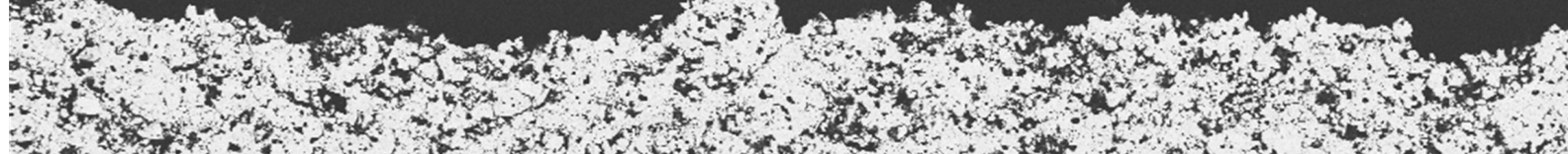

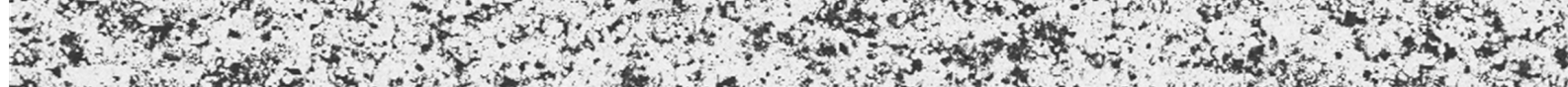
T.

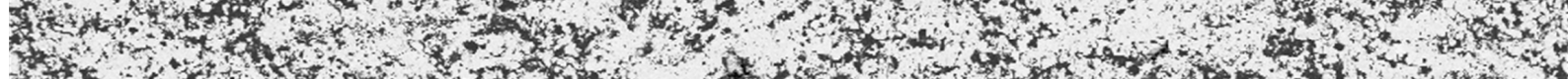

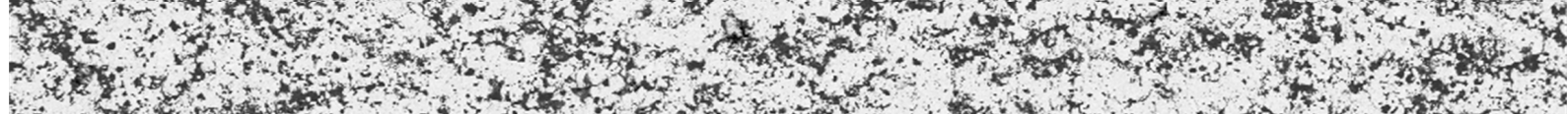

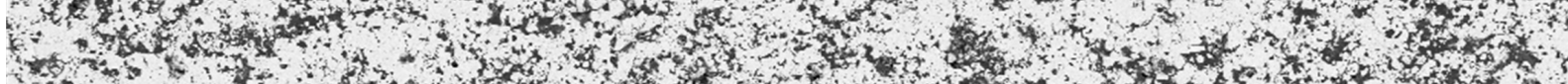

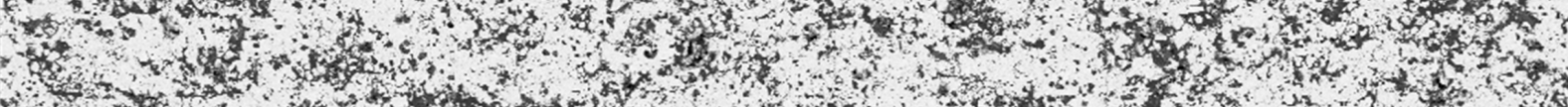

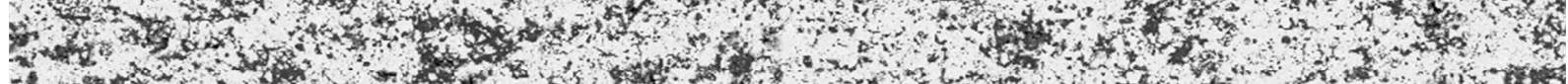

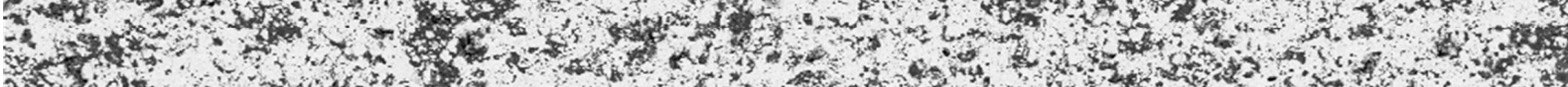

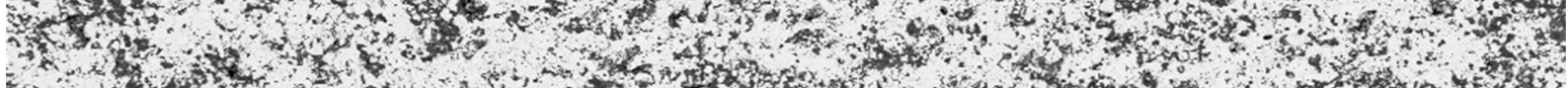

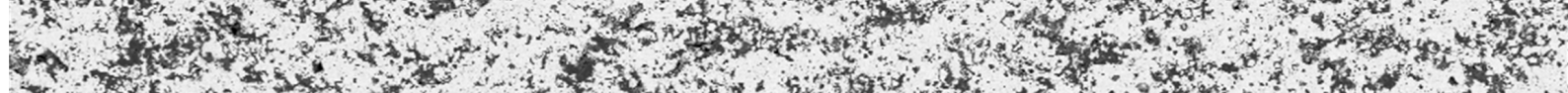

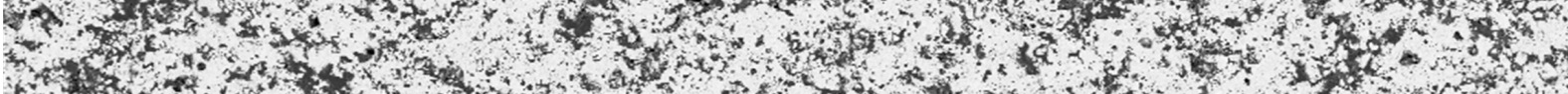

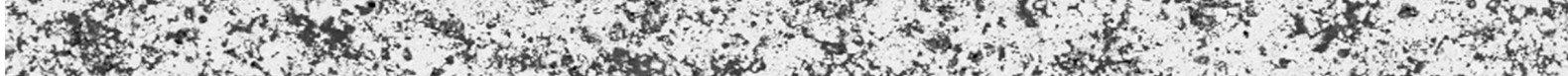

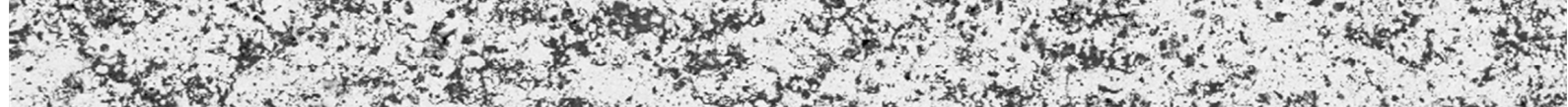
1.

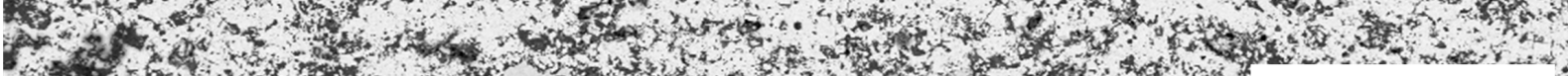
(1) 

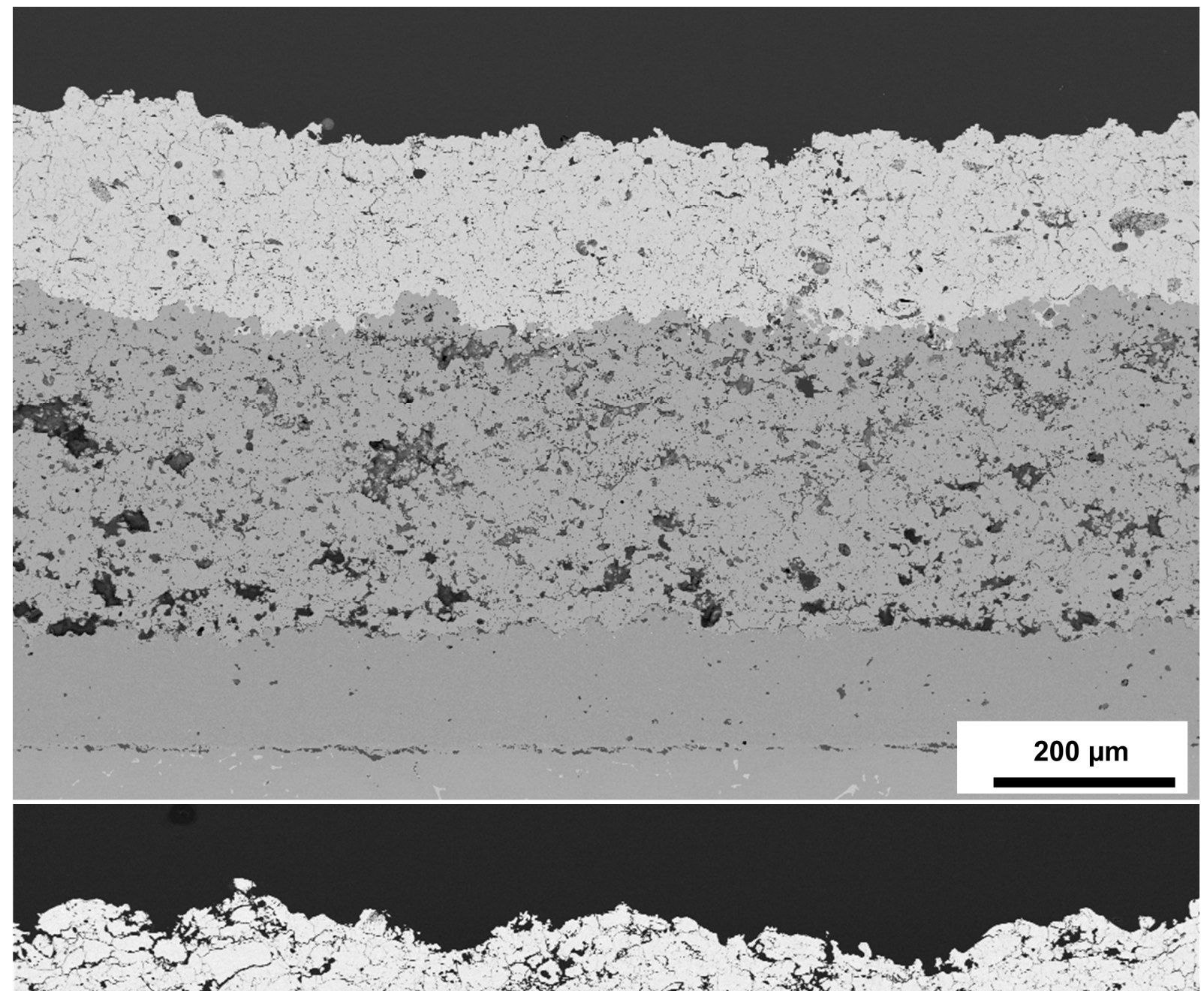

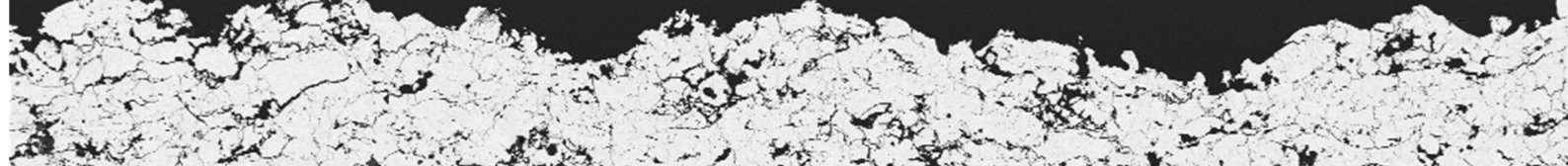

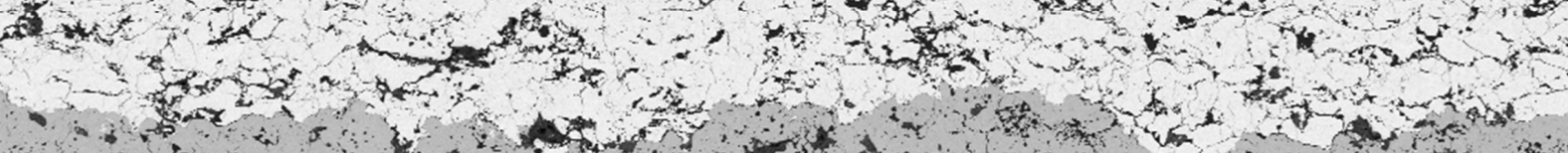

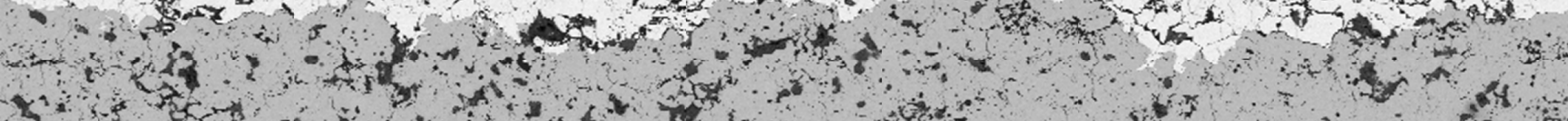

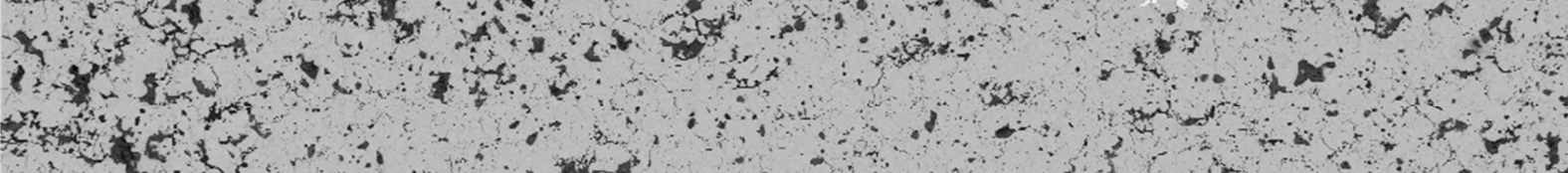

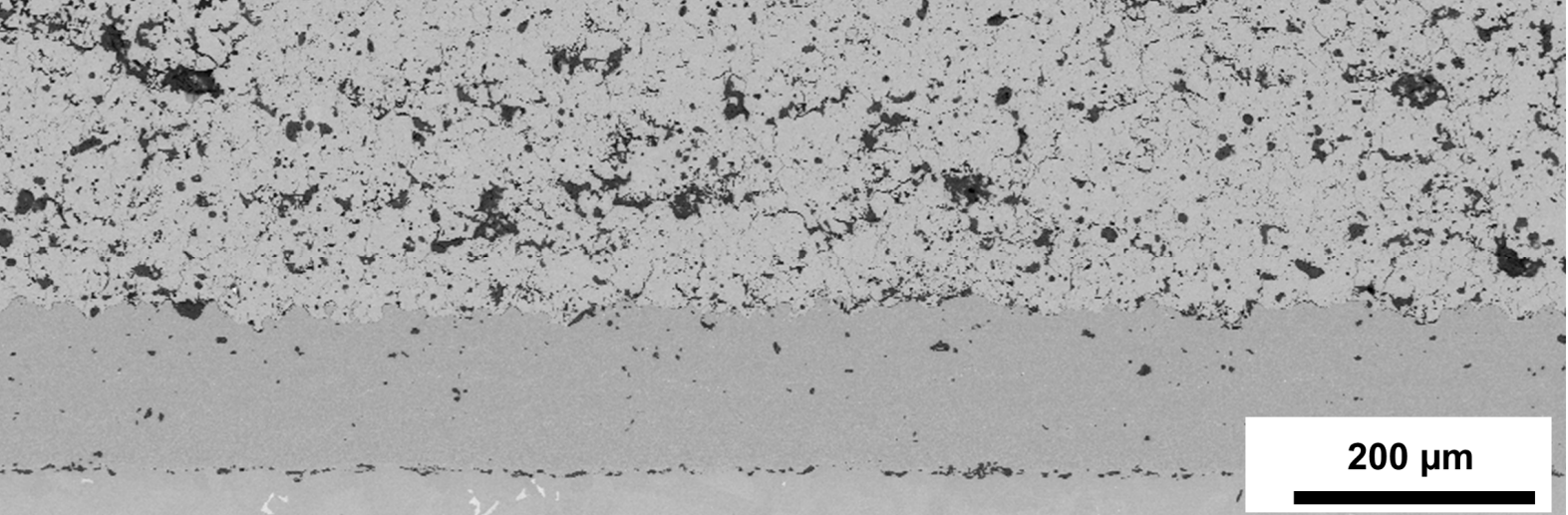


Figure 1

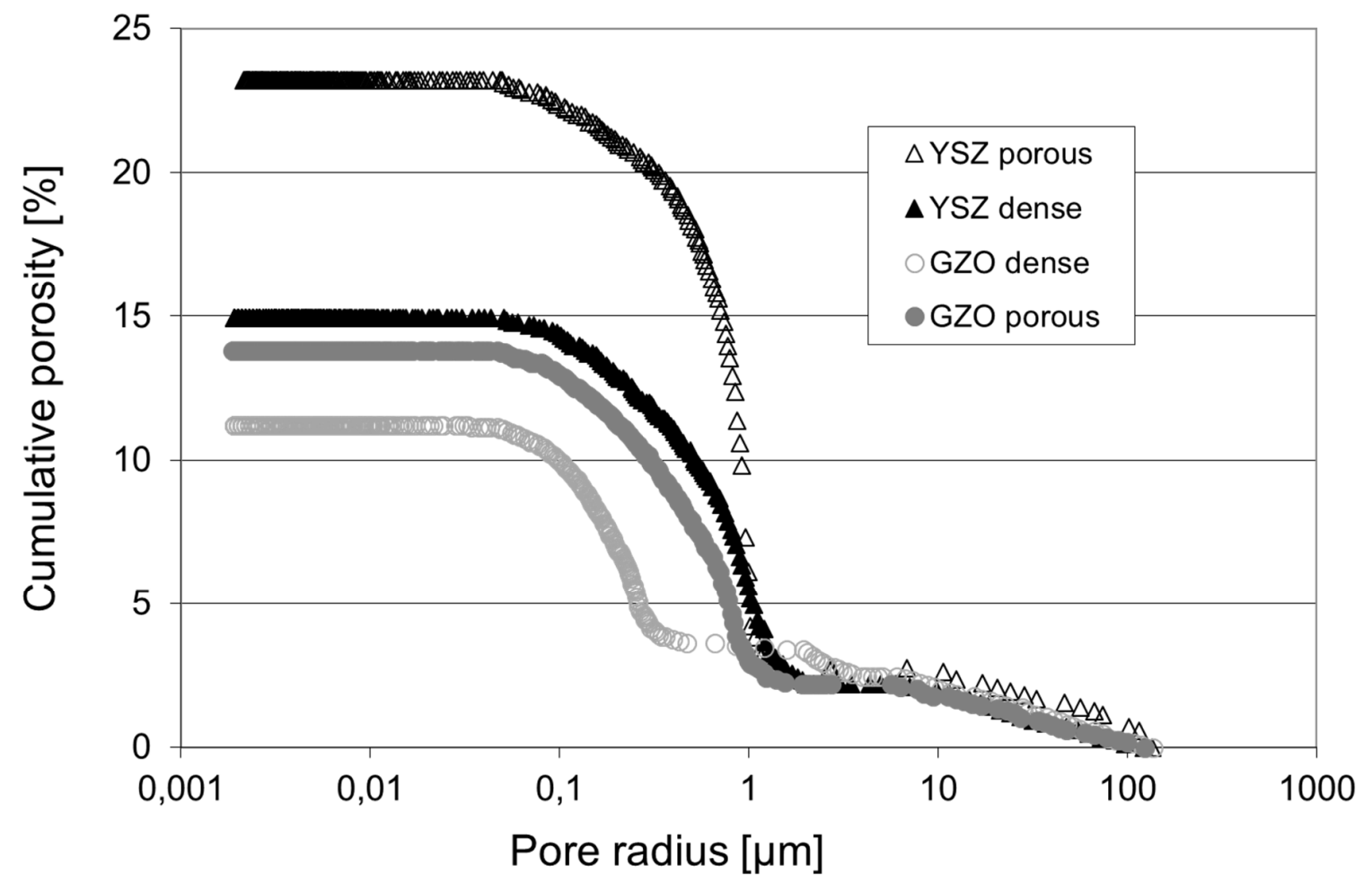

Figure2 


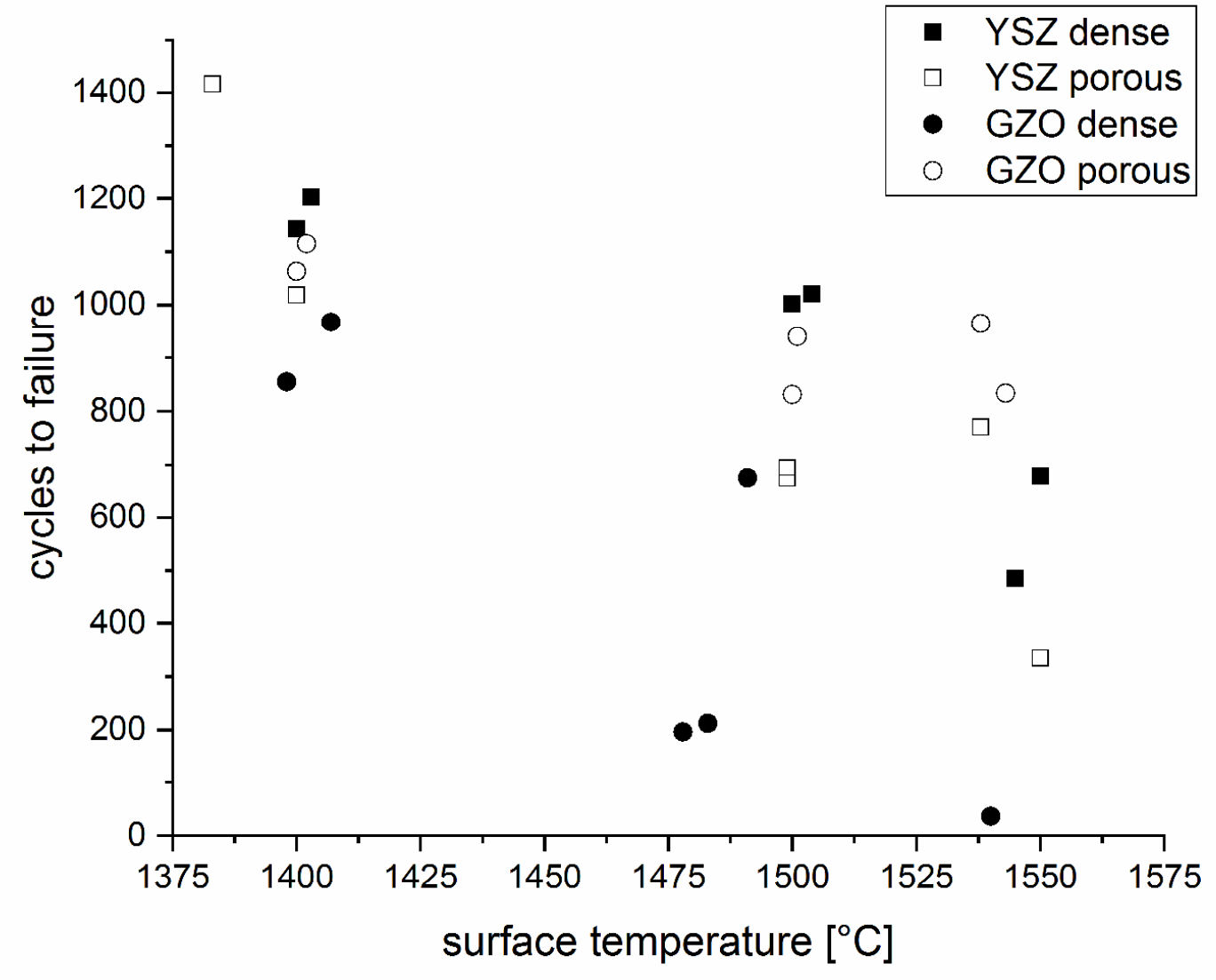

Figure 3 

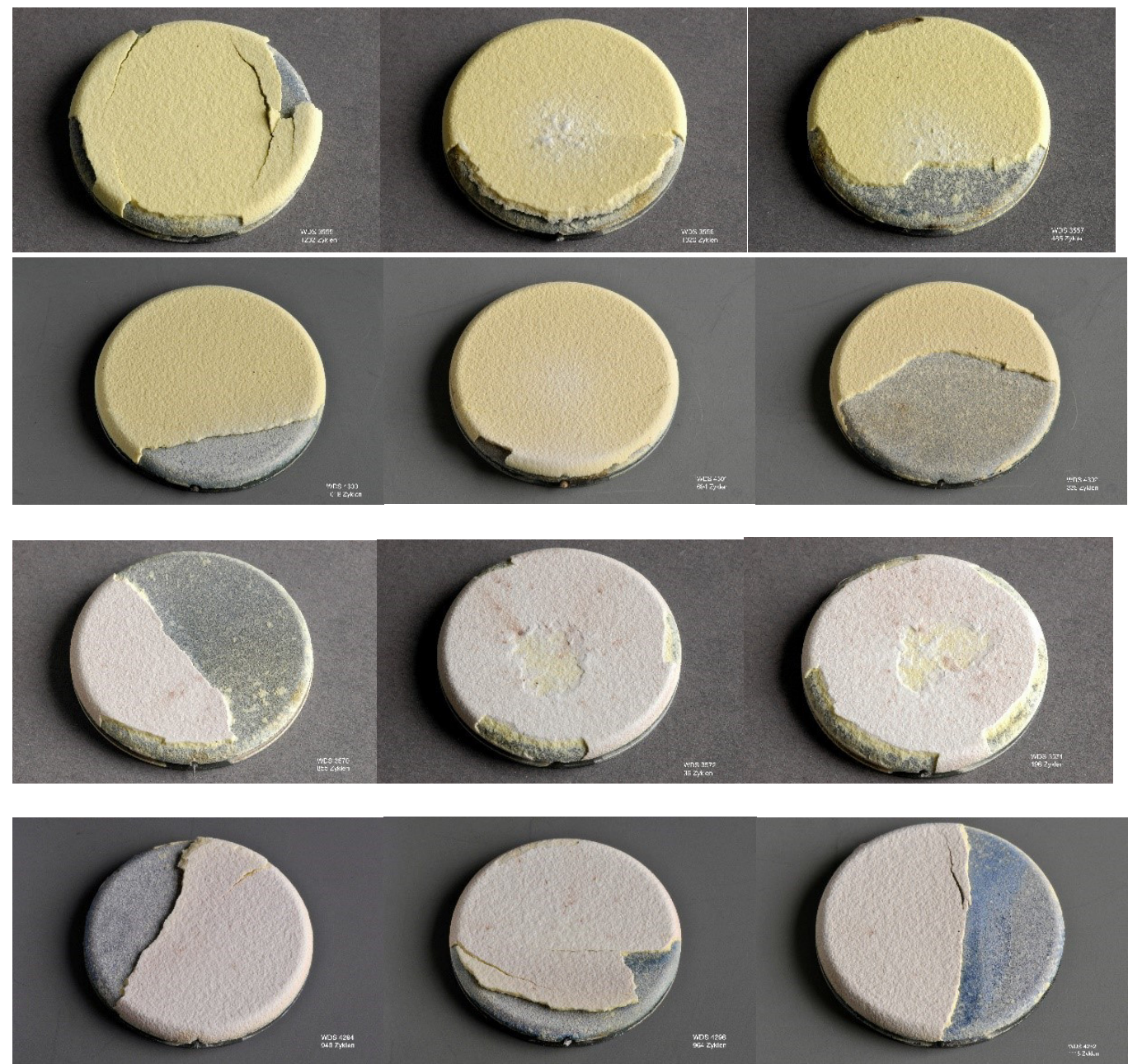

Figure 4 


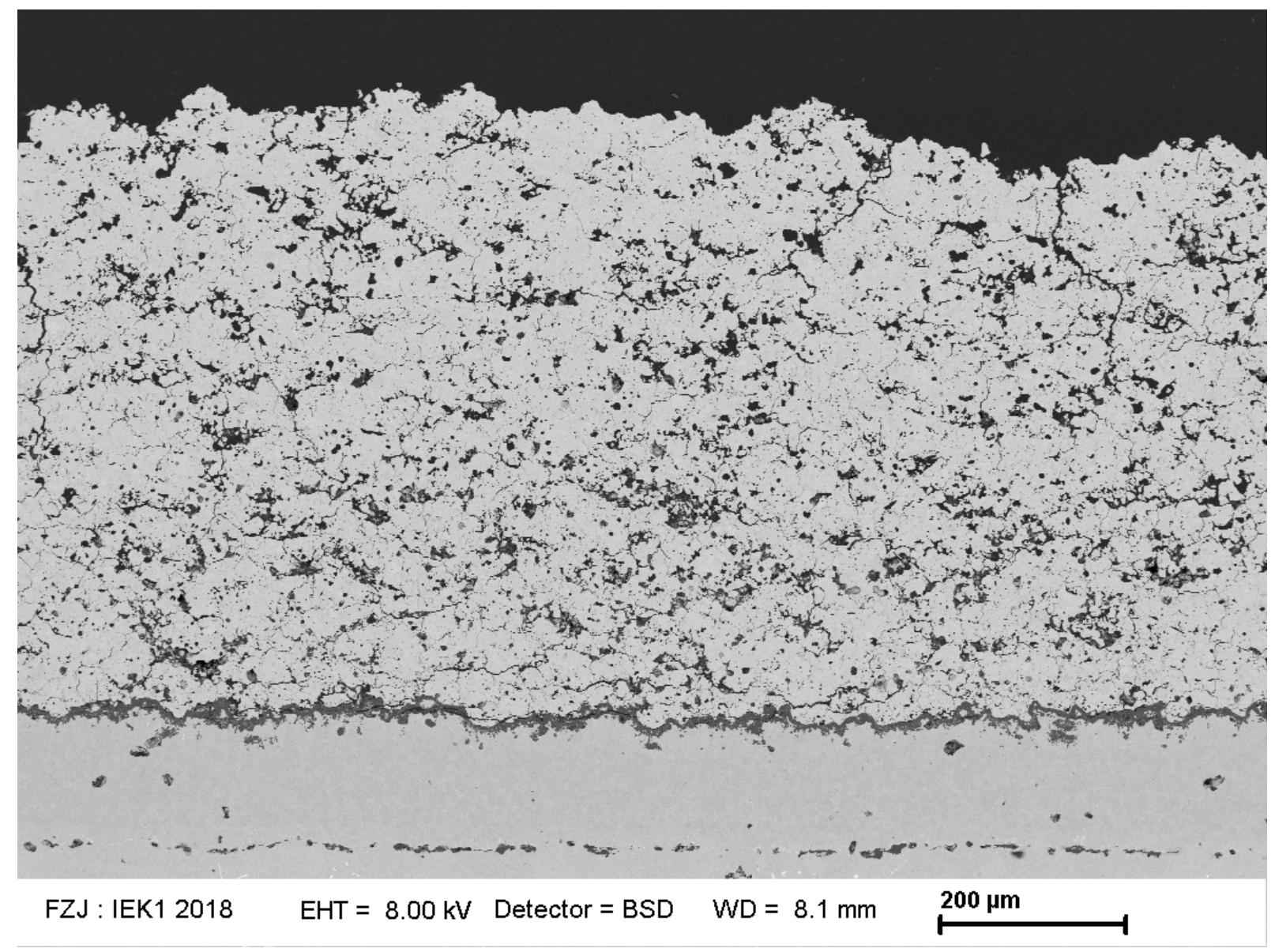




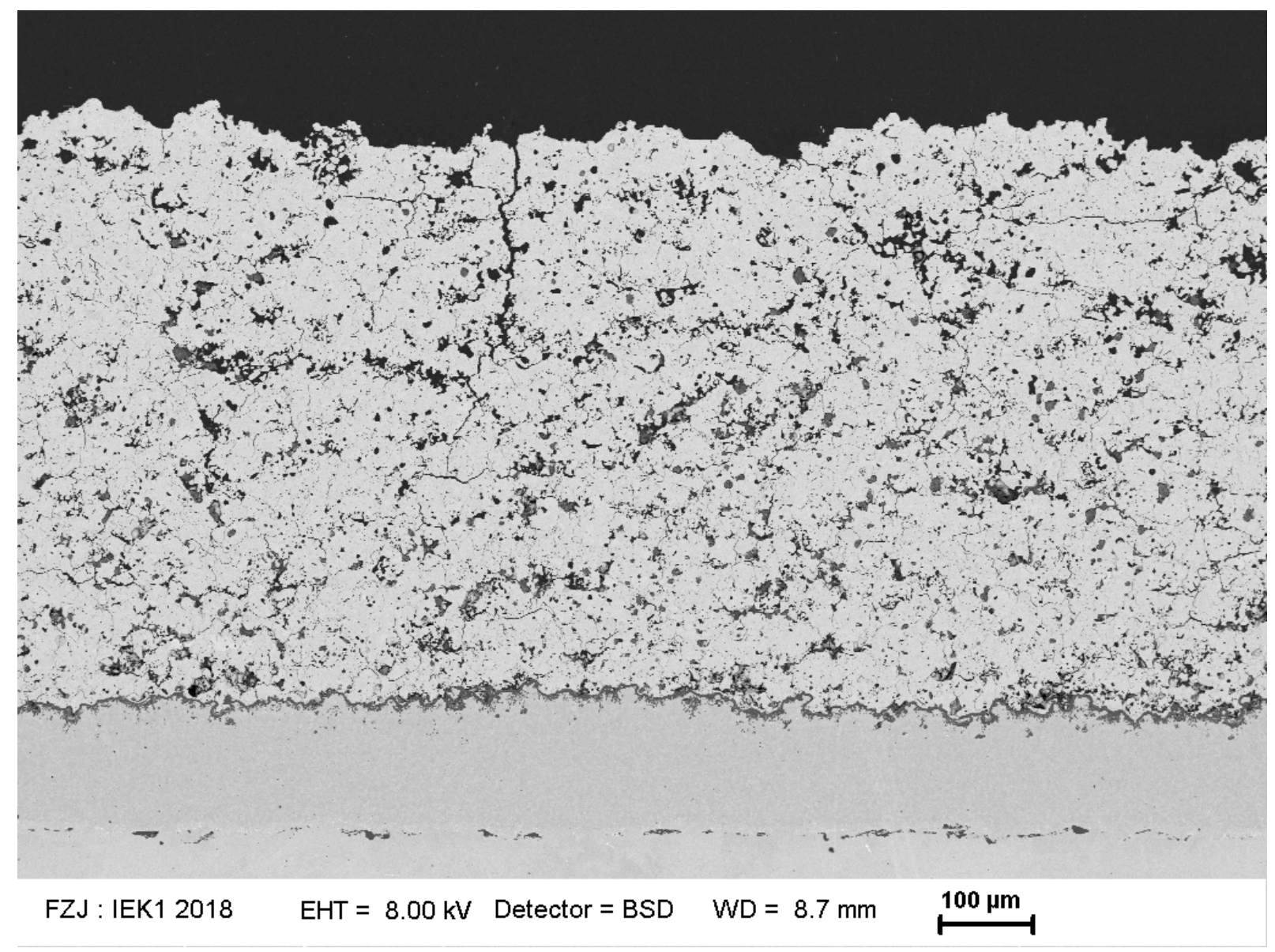




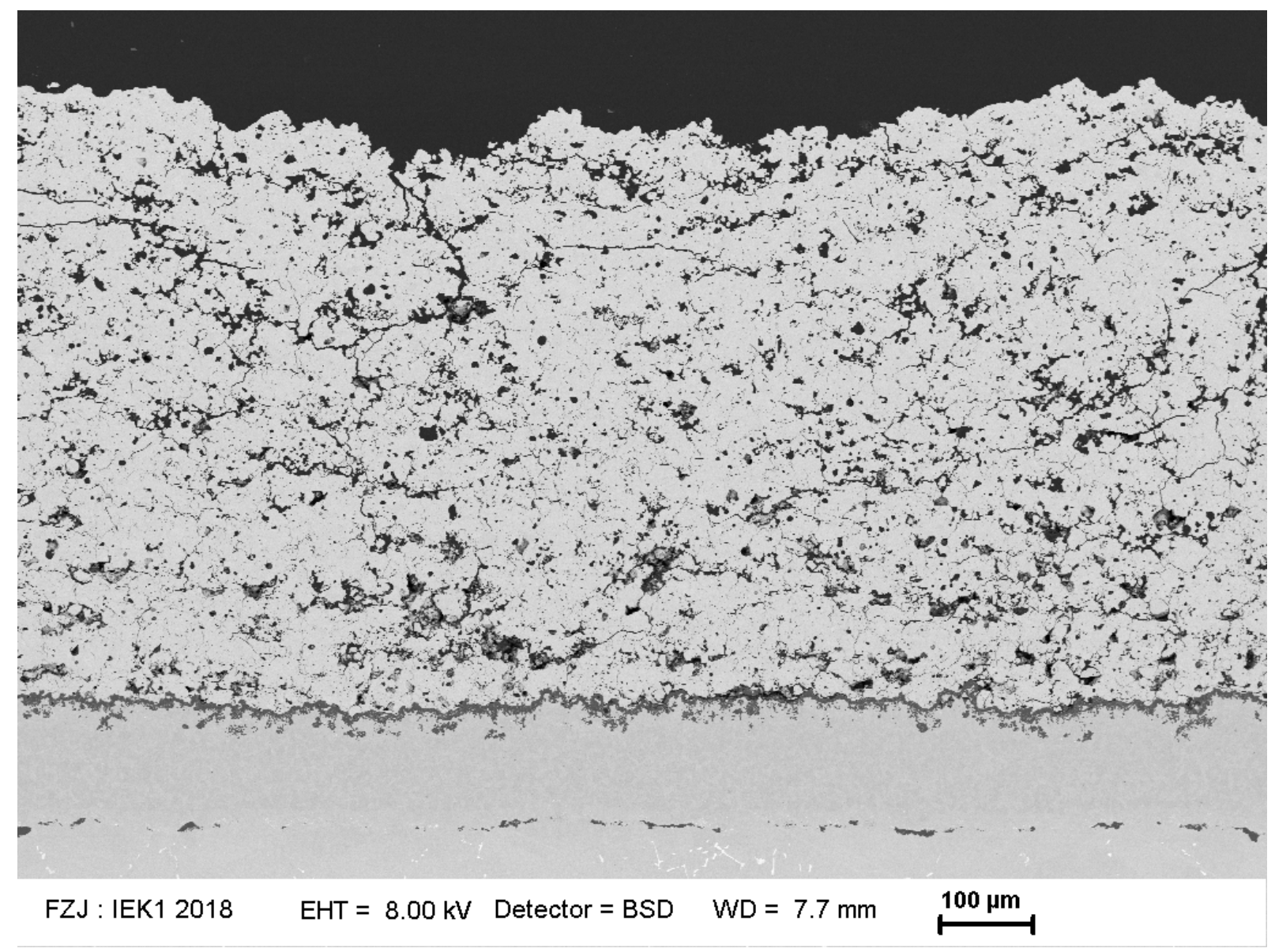




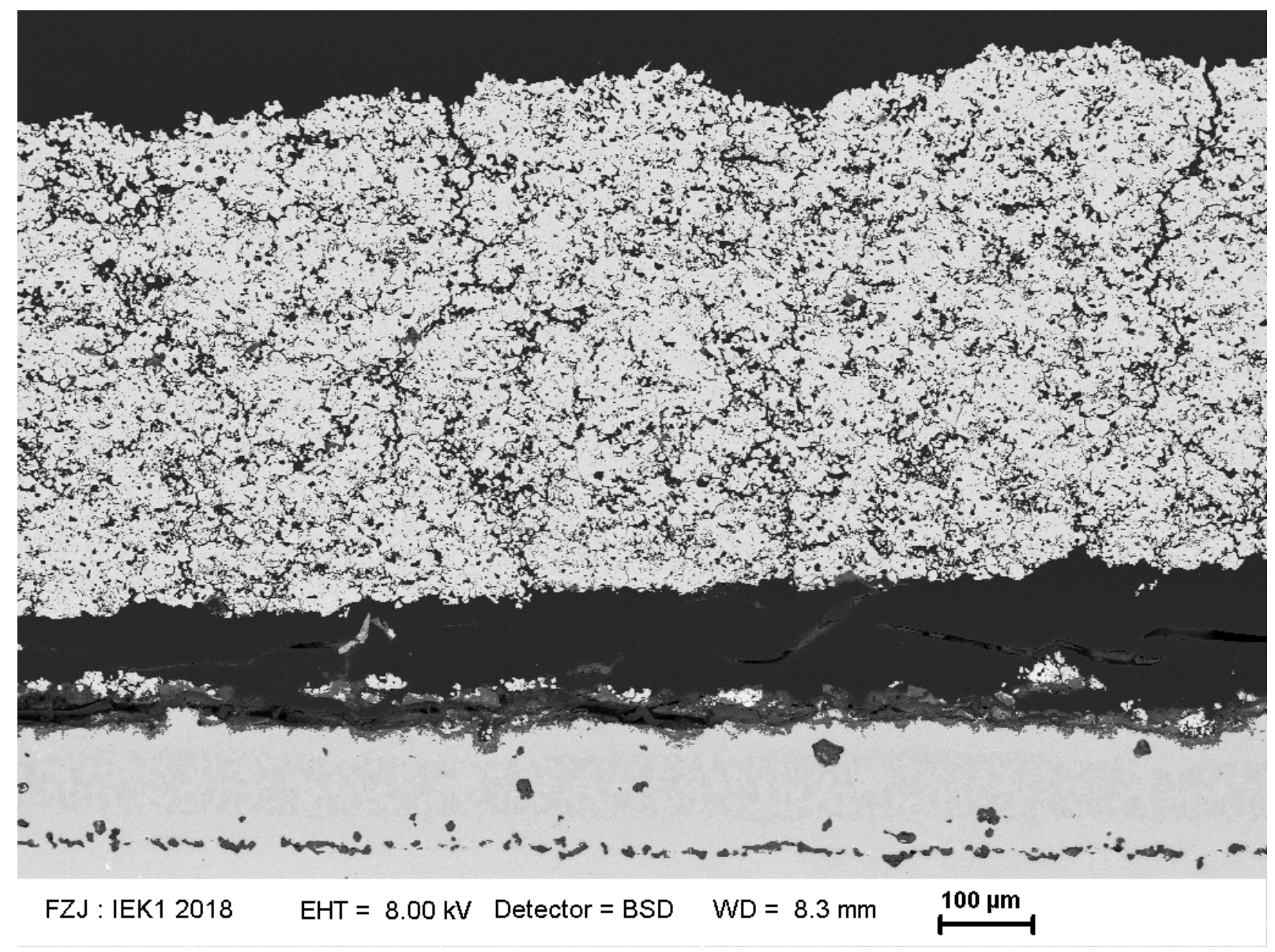




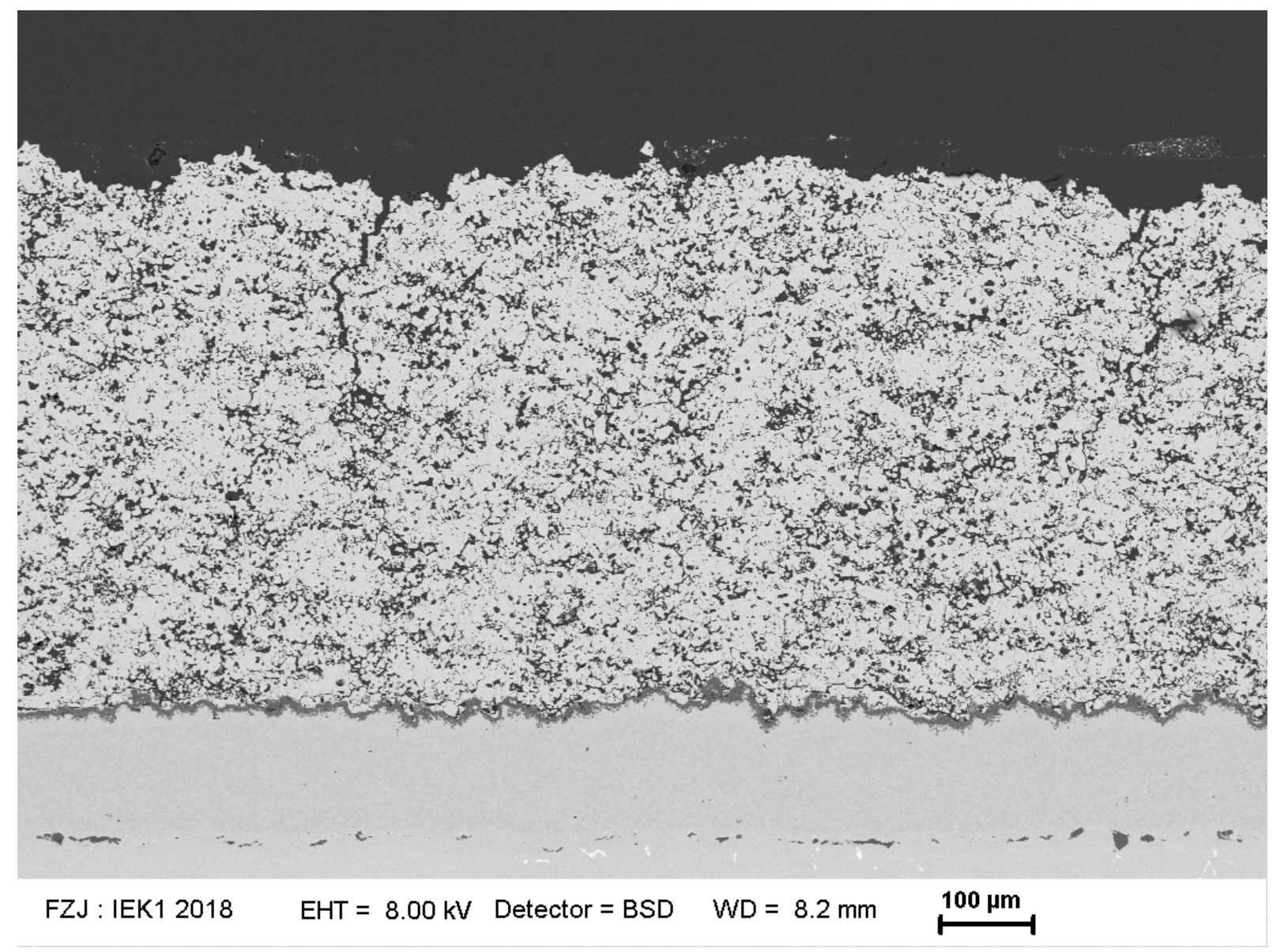




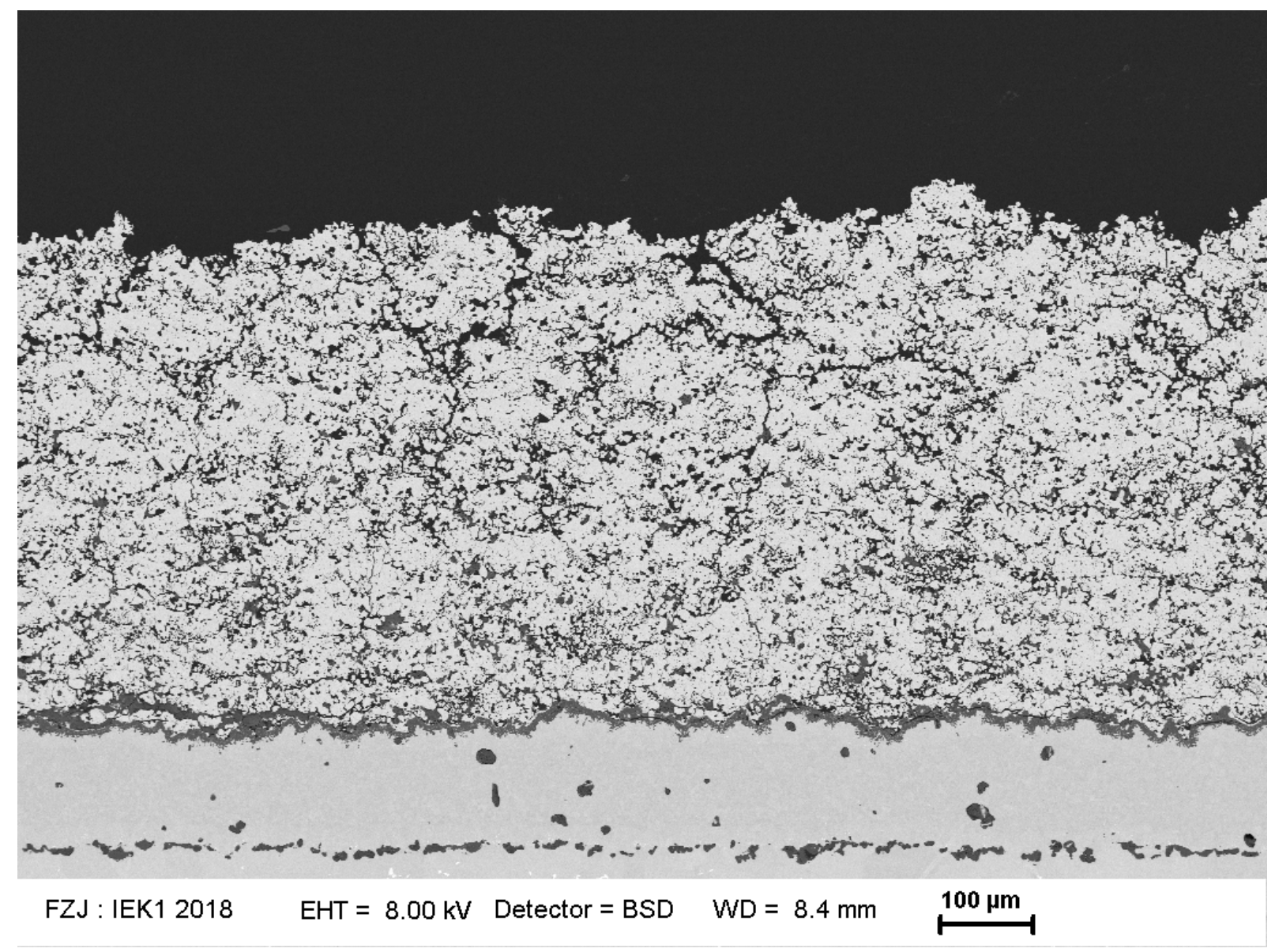




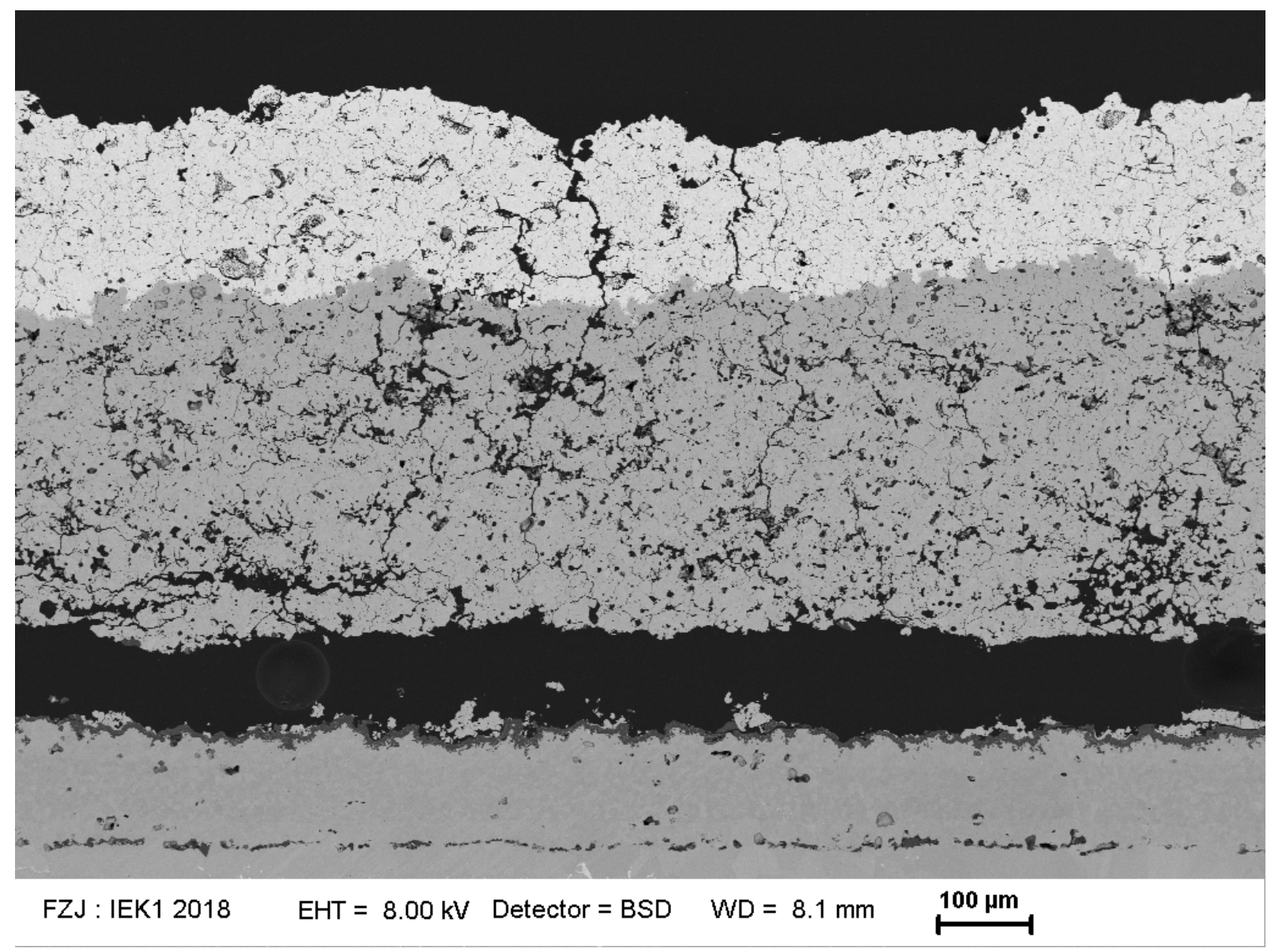




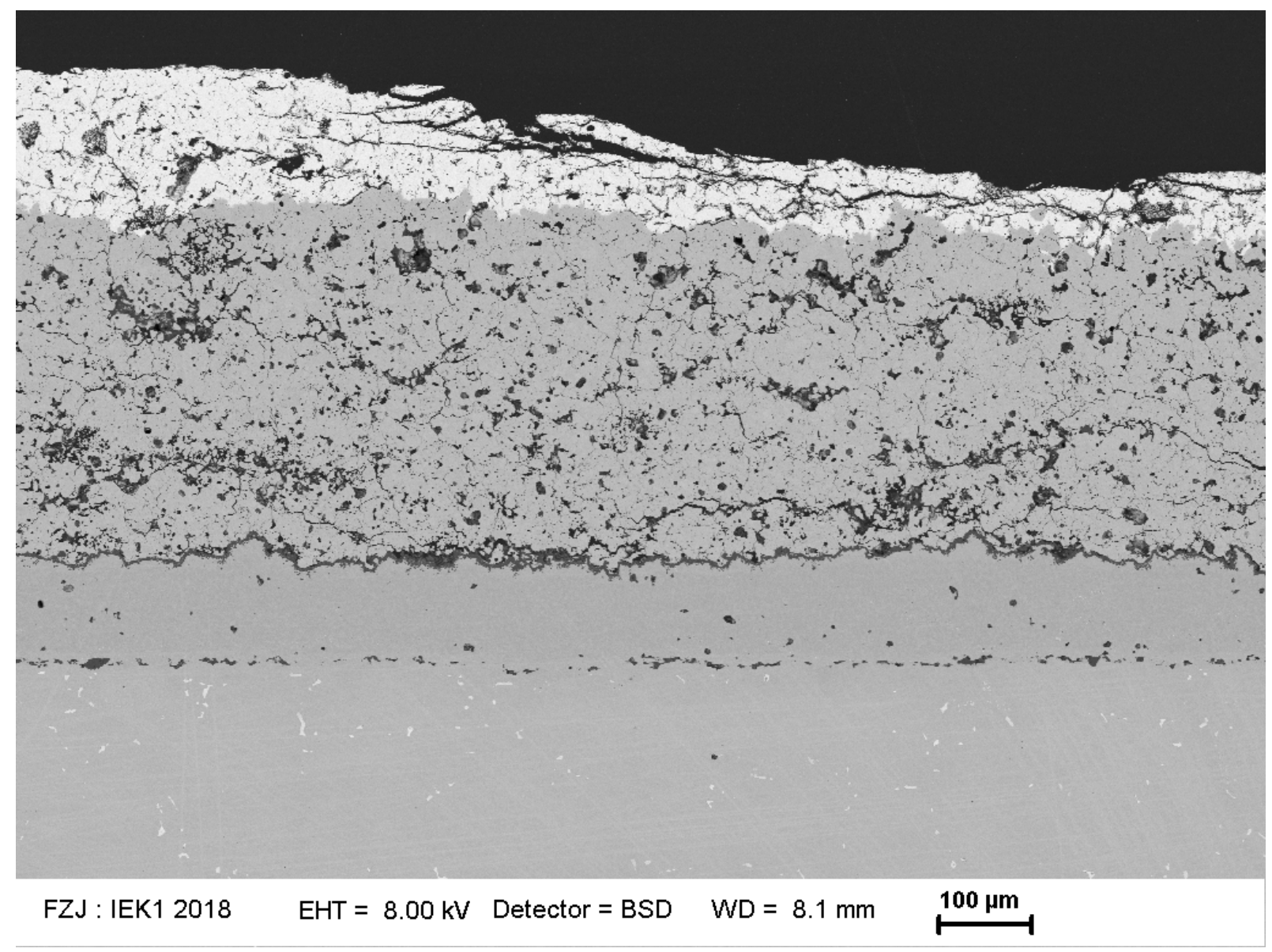




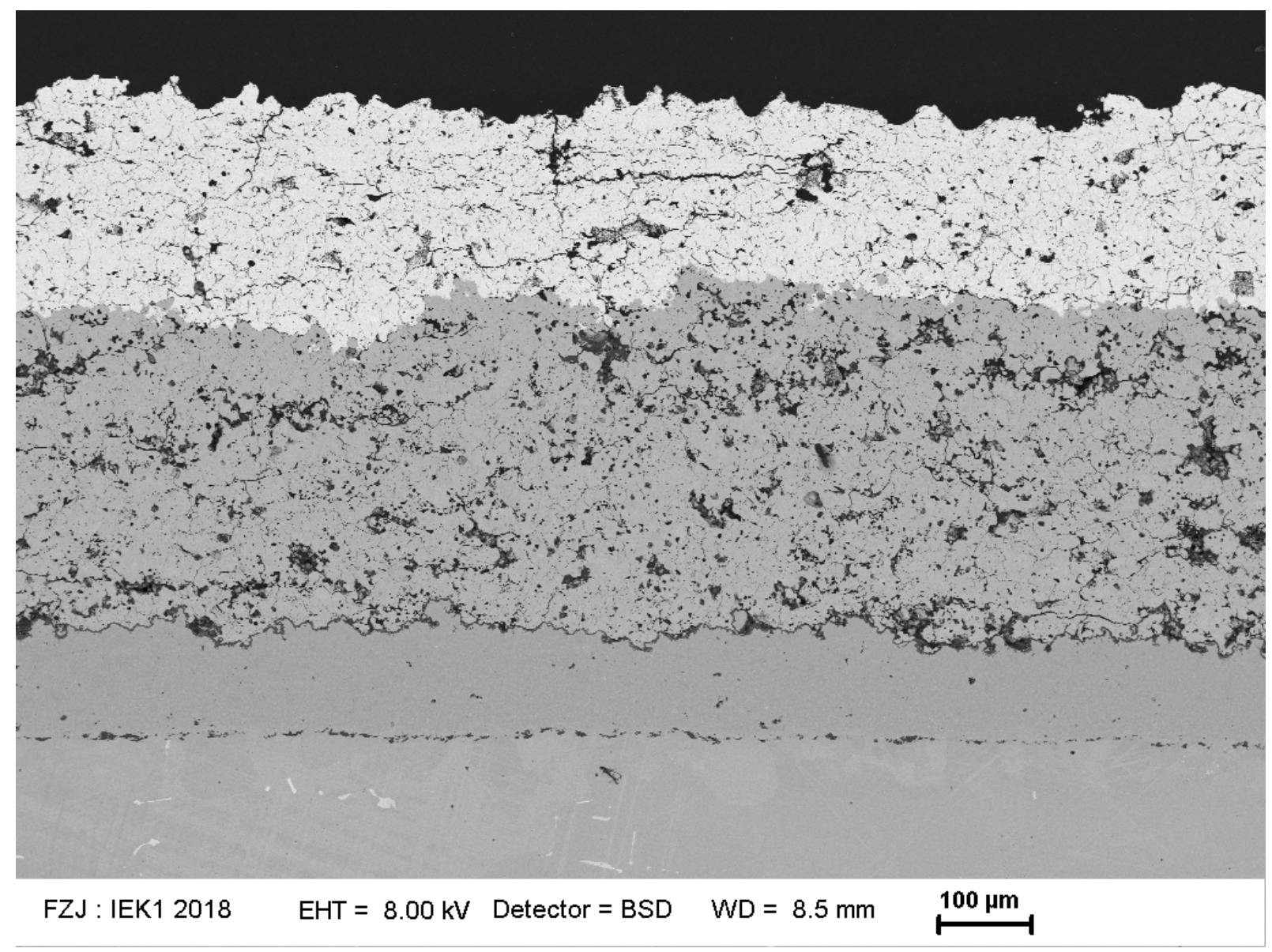




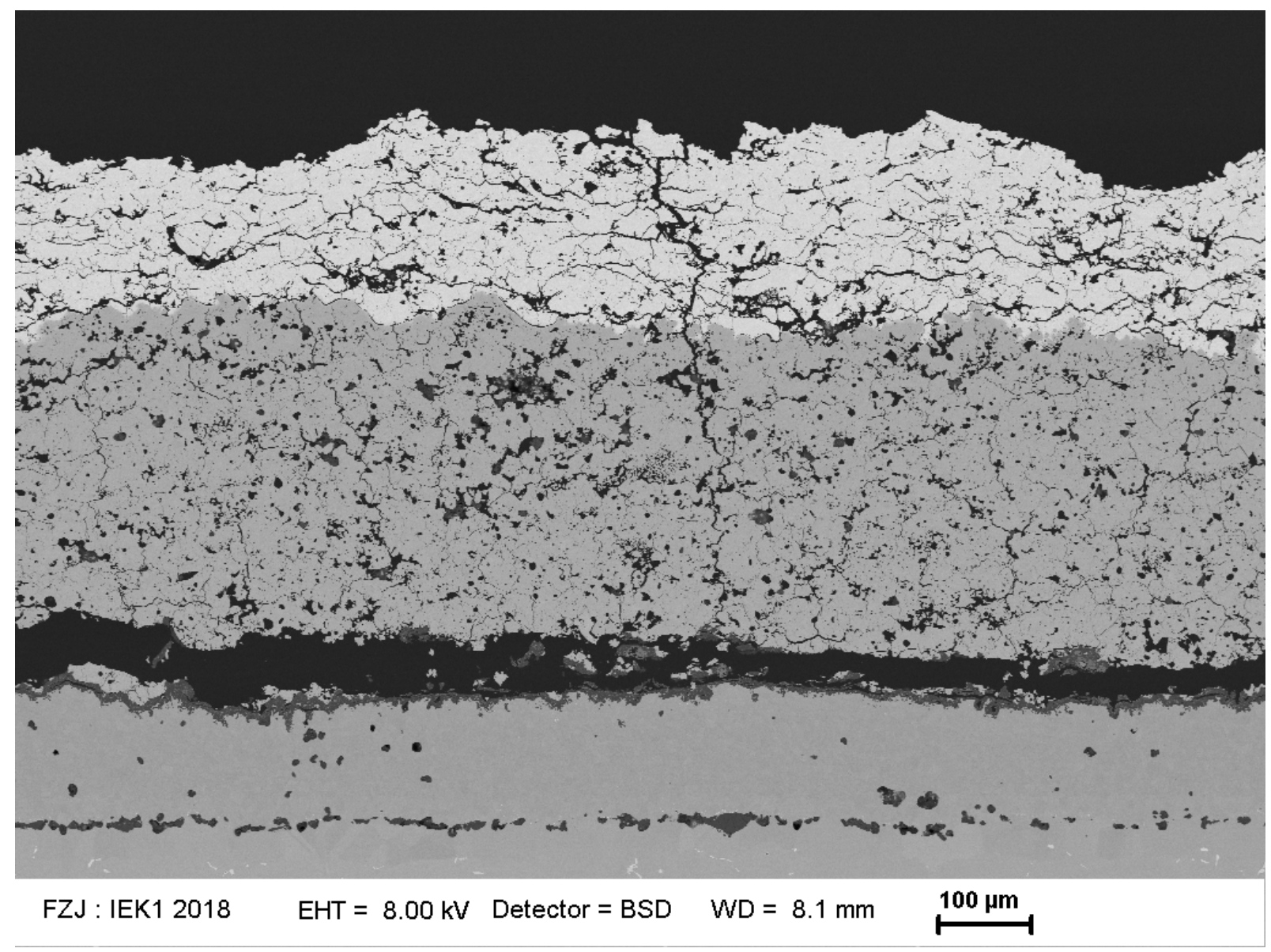




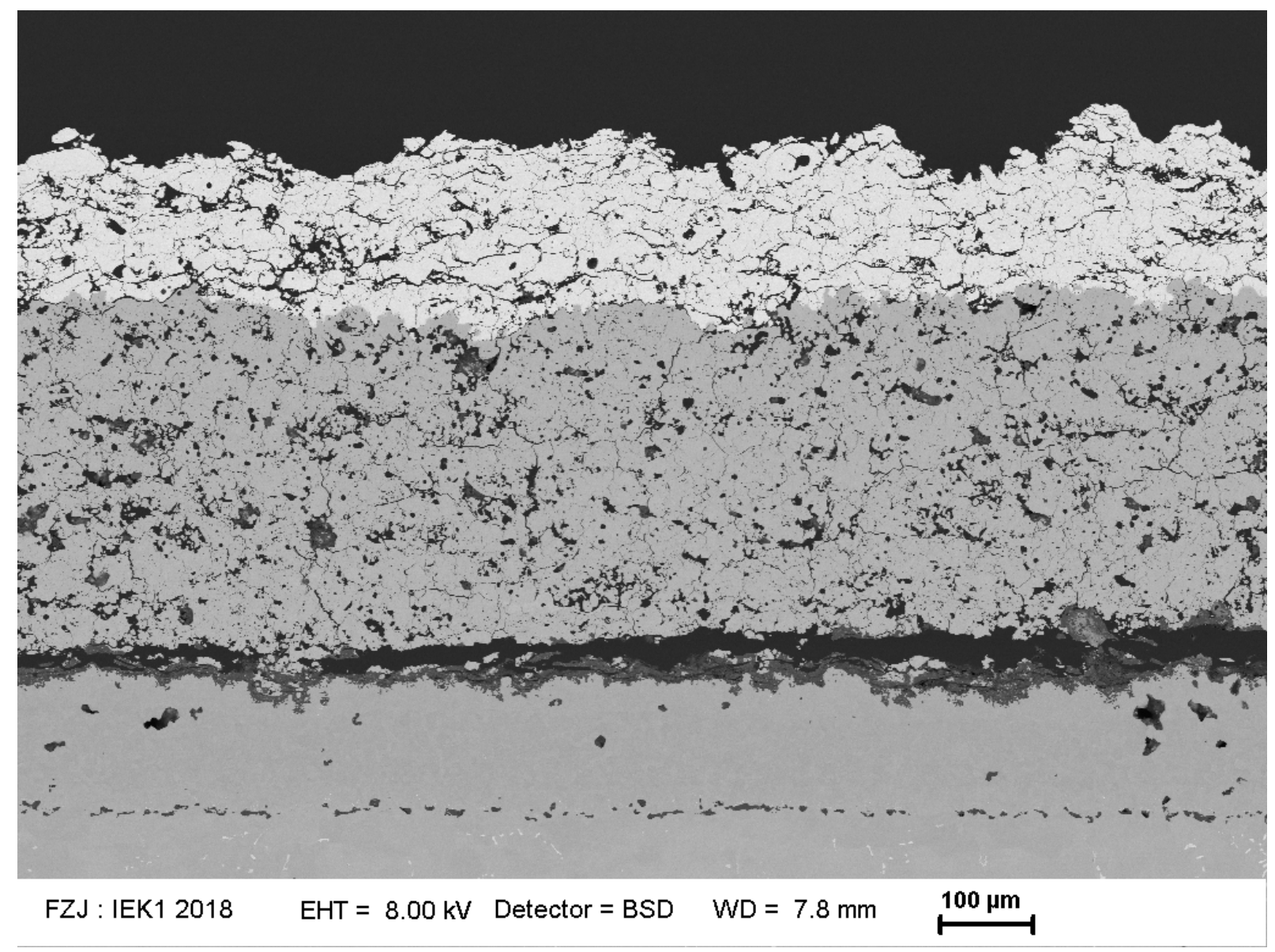




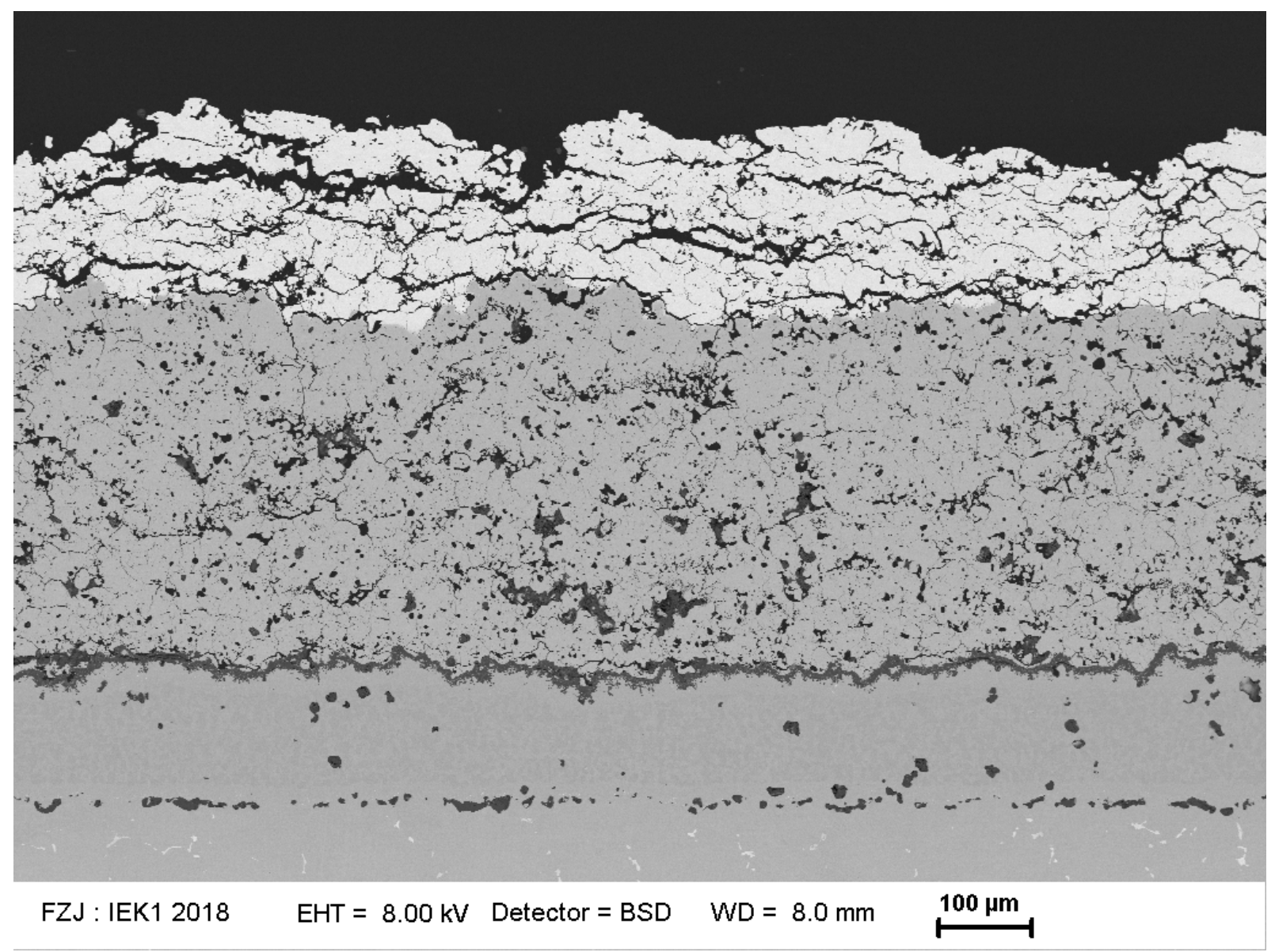

Figure 5 


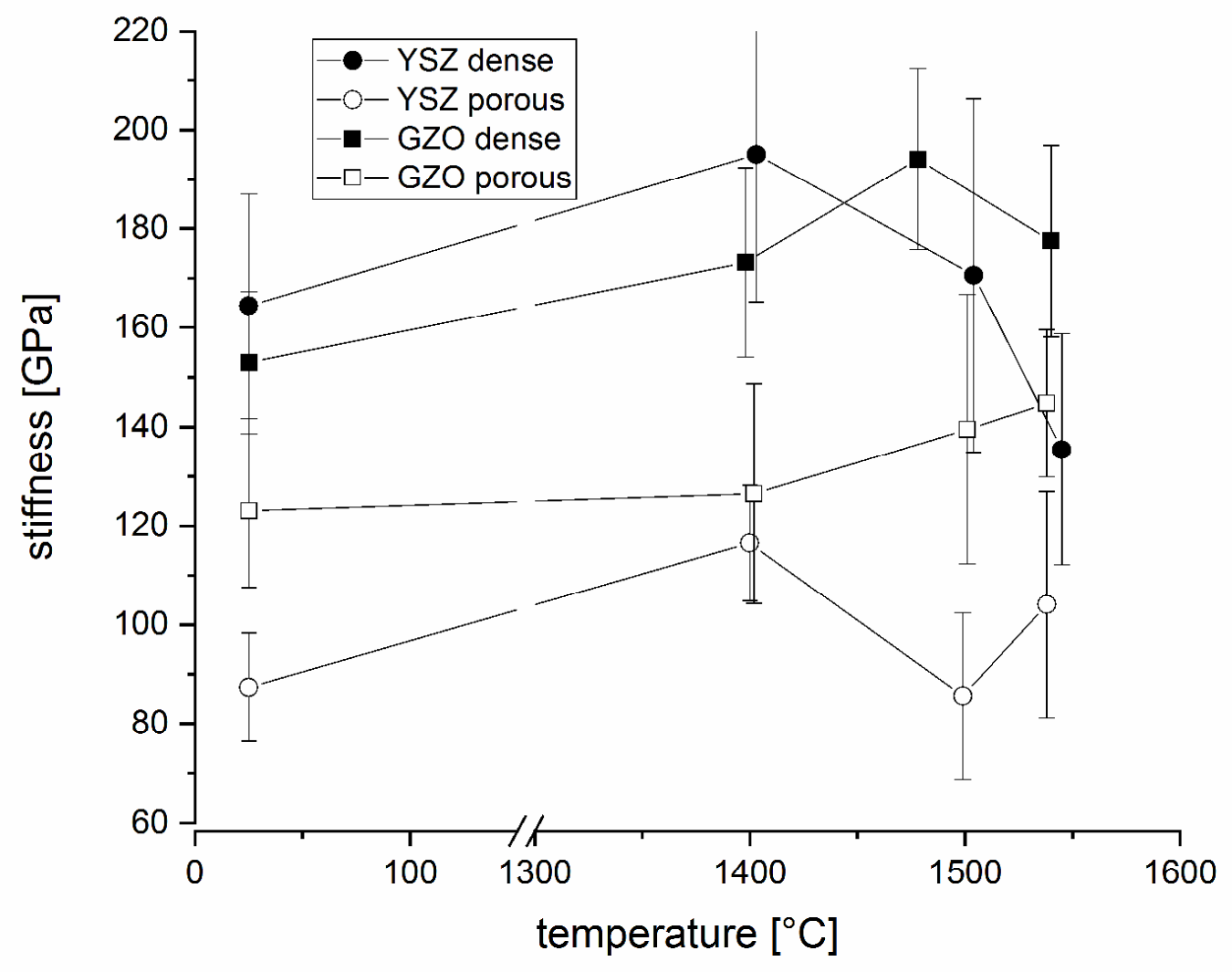




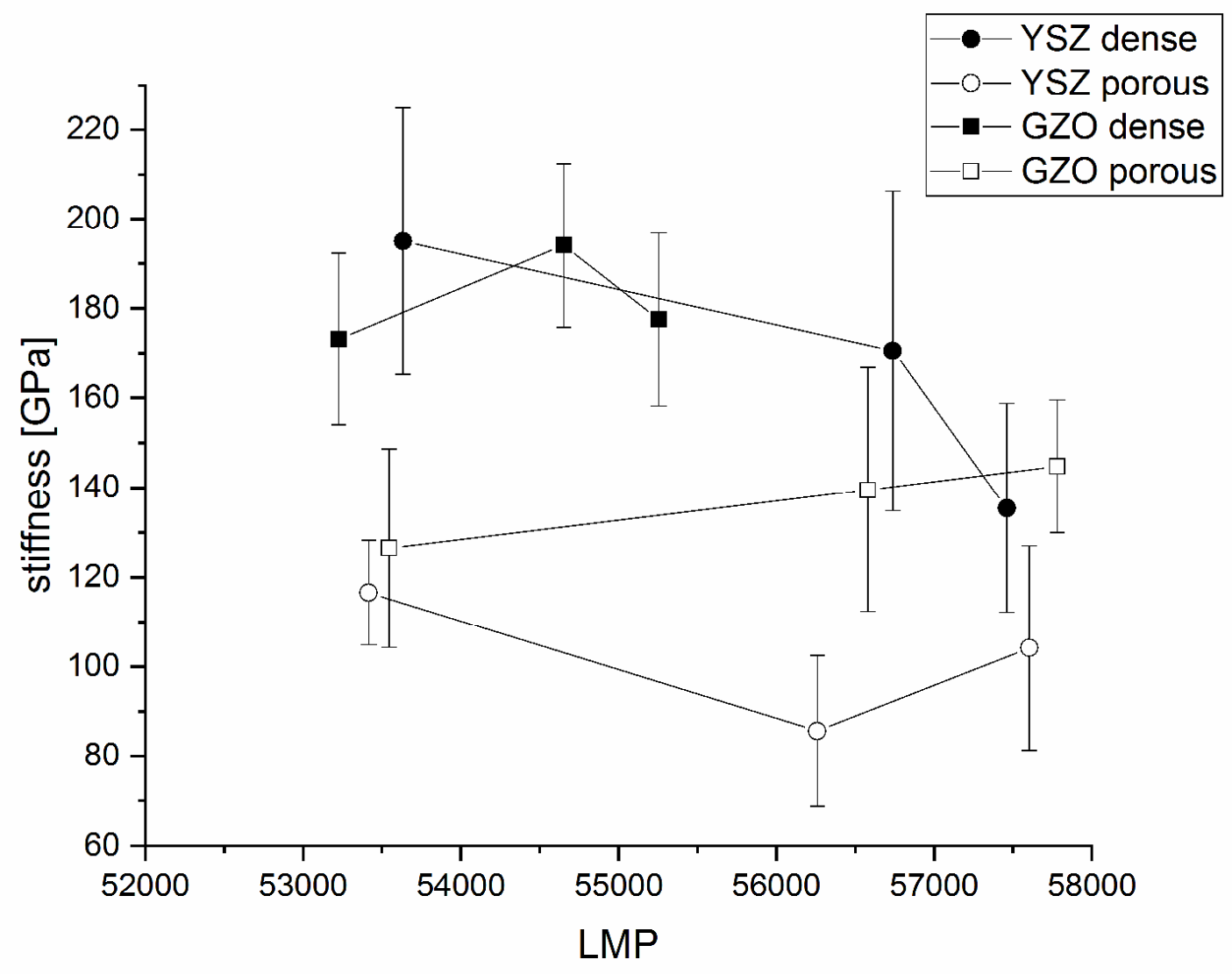

Figure 6 

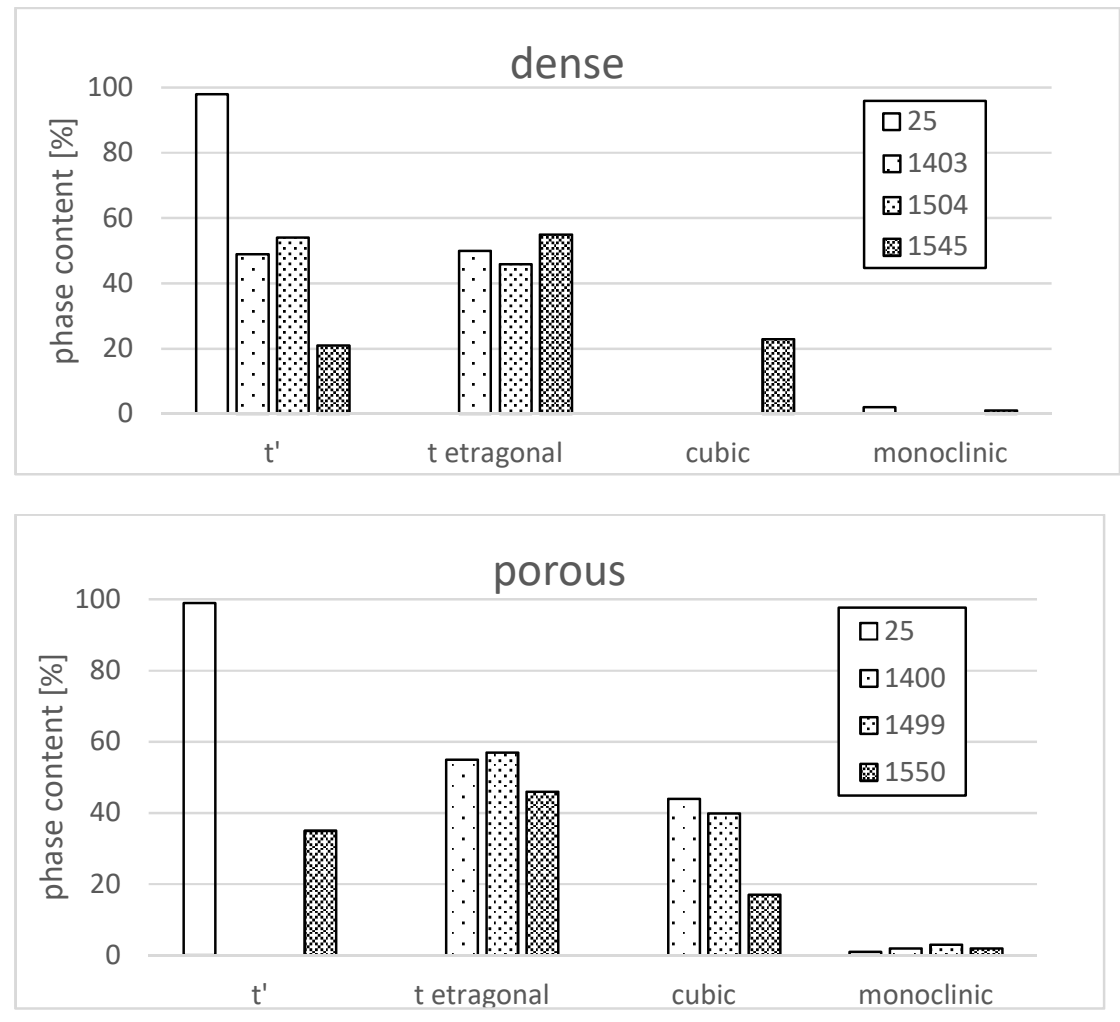

Figure 7 


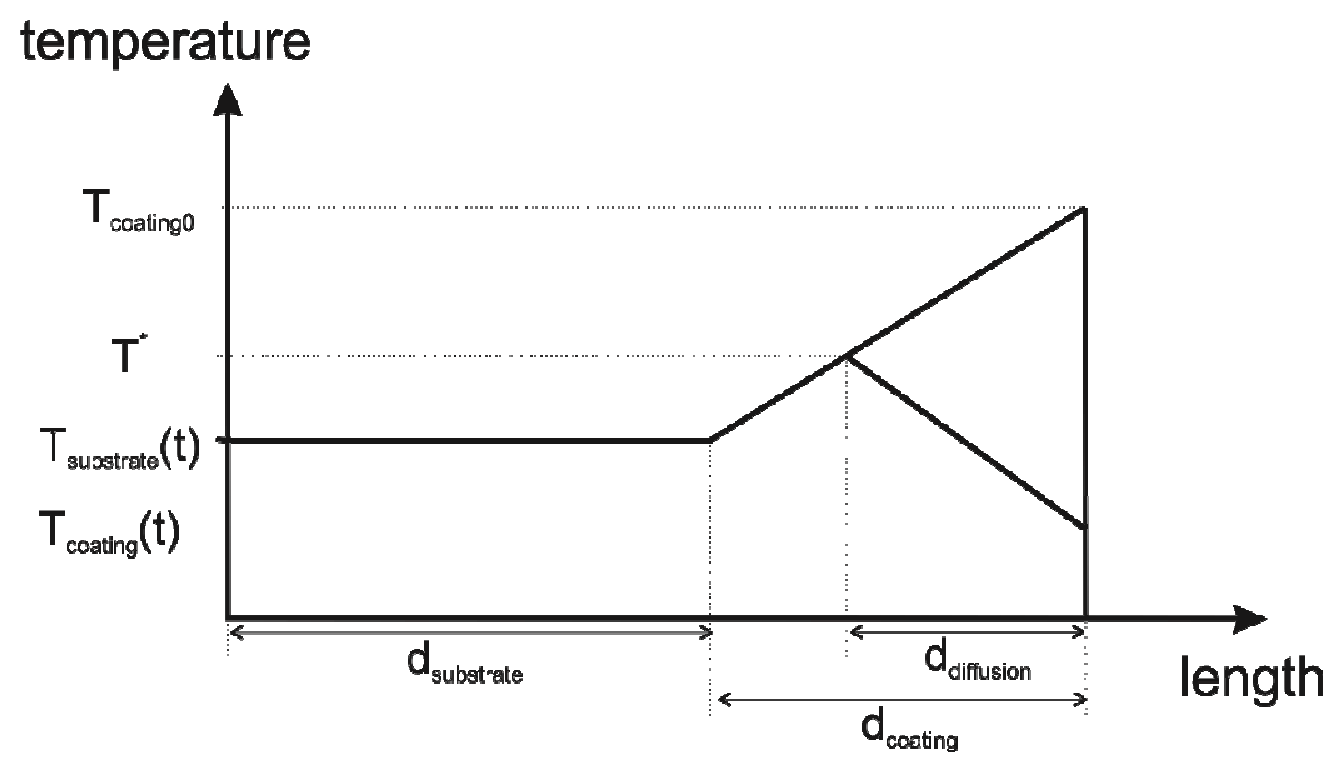

Figure 8

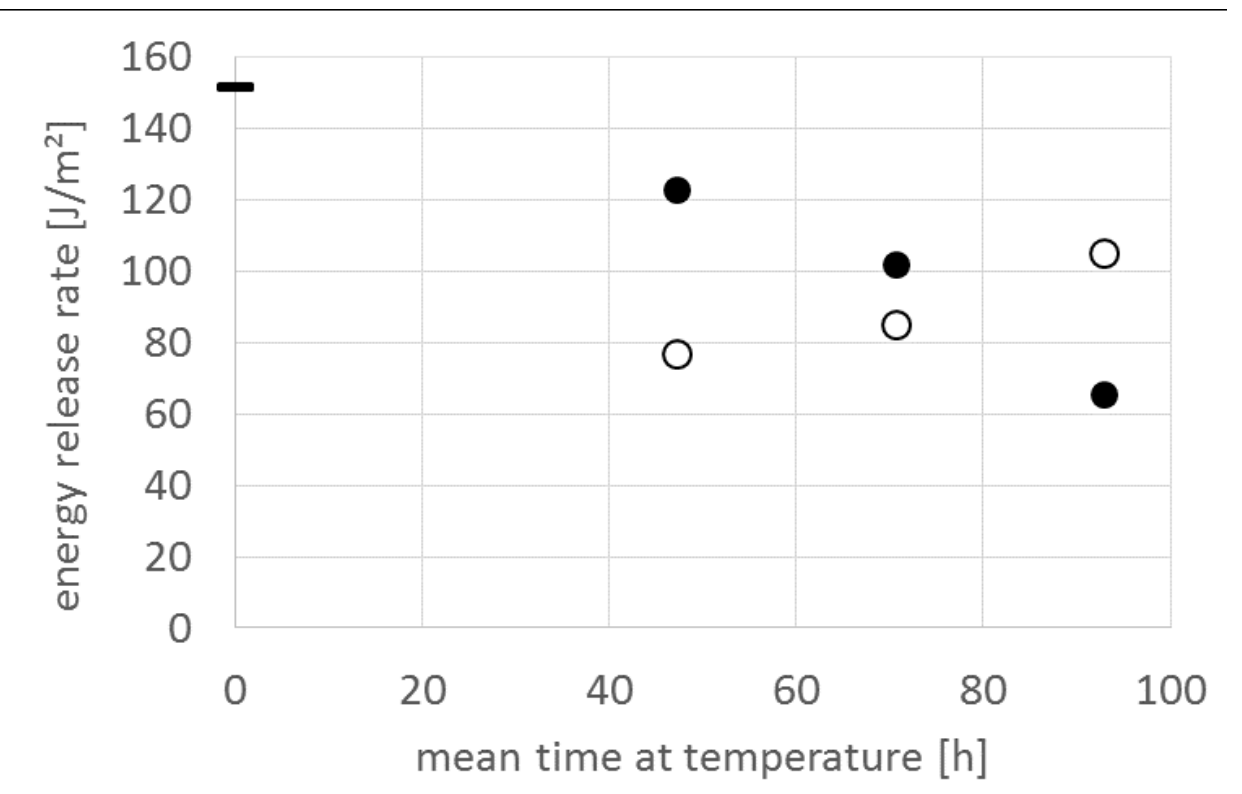

Figure 9 